\title{
La cerámica del yacimiento arqueológico de Castillejo del Bonete (Terrinches, Ciudad Real). Estudio morfológico y tecnólogico
}

\author{
The Ceramic Assemblage from the Castillejo del Bonete (Terrinches, \\ Ciudad Real) Archaeological Site. \\ A Morphological and Technological Approach
}

\author{
Sergio Fernández Martín \\ Arquenatura s.l. Güéjar Sierra, Granada \\ info@arquenatura.com \\ Luis Benítez de Lugo EnRich \\ Dpto. de Prehistoria y Arqueología UNED. Valdepeñas, Ciudad Real \\ lbenitez@valdepenas.uned.es \\ Norberto Palomares Zumajo \\ Anthropos, s.1. Valdepeñas, Ciudad Real \\ anthropos@estudio-arqueologia.es
}

Recibido: 05-09-2014

Aceptado:12-12-2014

\begin{abstract}
RESUMEN
El presente trabajo incluye el estudio de un amplio conjunto cerámico perteneciente al yacimiento arqueológico de la Edad del Cobre y Edad del Bronce de Castillejo del Bonete. La muestra fue recuperada de distintas áreas del asentamiento durante la campaña de excavación de 2012. La investigación ha tenido como fin conocer mejor la relación forma-función de las vasijas, su proceso de fabricación, así como el modelo productivo y las posibles manifestaciones simbólicas presentes en el repertorio analizado. La metodología utilizada para cumplir con los objetivos se ha basado en la recopilación de datos, considerando una serie de variables morfológicas y tecnológicas, y su procesamiento con el empleo de técnicas estadísticas sencillas.
\end{abstract}

Palabras Clave: cerámica, Calcolítico, Edad del Bronce, estudio tipológico, tecnología, morfología.

\begin{abstract}
This paper is focused on the ceramic assemblage from the Copper and Bronze Age site of Castillejo del Bonete. The pottery sample, documented in the fieldworks undertaken in 2012, has been studied from different point of views including the relationship between shape and function, the manufacturing techniques, patterns of production and their symbolic meanings. To this end, different morphological and technological properties of the pottery vessels have been analysed by means of statistical methods.
\end{abstract}

Key words: Pottery, Chalcolithic, Bronze Age, Tipological Research, Technology, Morphology. 


\section{Introducción}

Castillejo del Bonete se encuentra en el borde meridional de la Meseta castellana y en la comarca del Campo de Montiel, al sureste de la provincia de Ciudad Real (Fig. 1).

El monumento fue utilizado durante el Calcolítico y las primeras fases de la Edad del Bronce. Se construyó sobre una ladera orientada al sur, desde la cual hay una excelente relación visual con una importante vía de comunicación histórica entre el Levante, la Submeseta Sur y la Alta Andalucía: la Vía Augusta (Benítez de Lugo et al. 2012; Sánchez Sánchez et al. 2012). El lugar es un paso estratégico entre las cuencas del Guadiana y del Guadalquivir, separadas por Sierra Morena.

La localización de Castillejo del Bonete al sureste de la provincia de Ciudad Real lo ubica en el borde meridional del territorio en el que tradicionalmente se ha situado a la Cultura del Bronce de La Mancha.
Al poco tiempo de comenzar los trabajos en el yacimiento quedaron al descubierto potentes arquitecturas de planta central. En campañas posteriores se descubrió un largo pasillo ciclópeo de más de veinte metros de longitud, el Corredor 1. También se detectó bajo esos potentes muros una cueva que era desconocida y al comienzo de los trabajos estaba oculta. En el momento actual se ha hecho evidente la existencia de dos grandes túmulos, uno de ellos edificado sobre una cueva natural, rodeada en su boca de potentes muros de contención que evitaban que las acumulaciones de tierra y piedras penetraran al interior de las galerías subterráneas.

El avance de las investigaciones desarrolladas (Benítez de Lugo et al. 2014a y 2014b; Polo et al. 2015; Salazar García et al. 2013) han permitido determinar que en Castillejo del Bonete hay una cueva que hace las funciones de cámara funeraria, que fue monumentalizada y adaptada para su uso en tiempos prehistóricos, resultando sellada y cayendo en el olvido tras el abandono del monumento durante la Edad del Bronce.

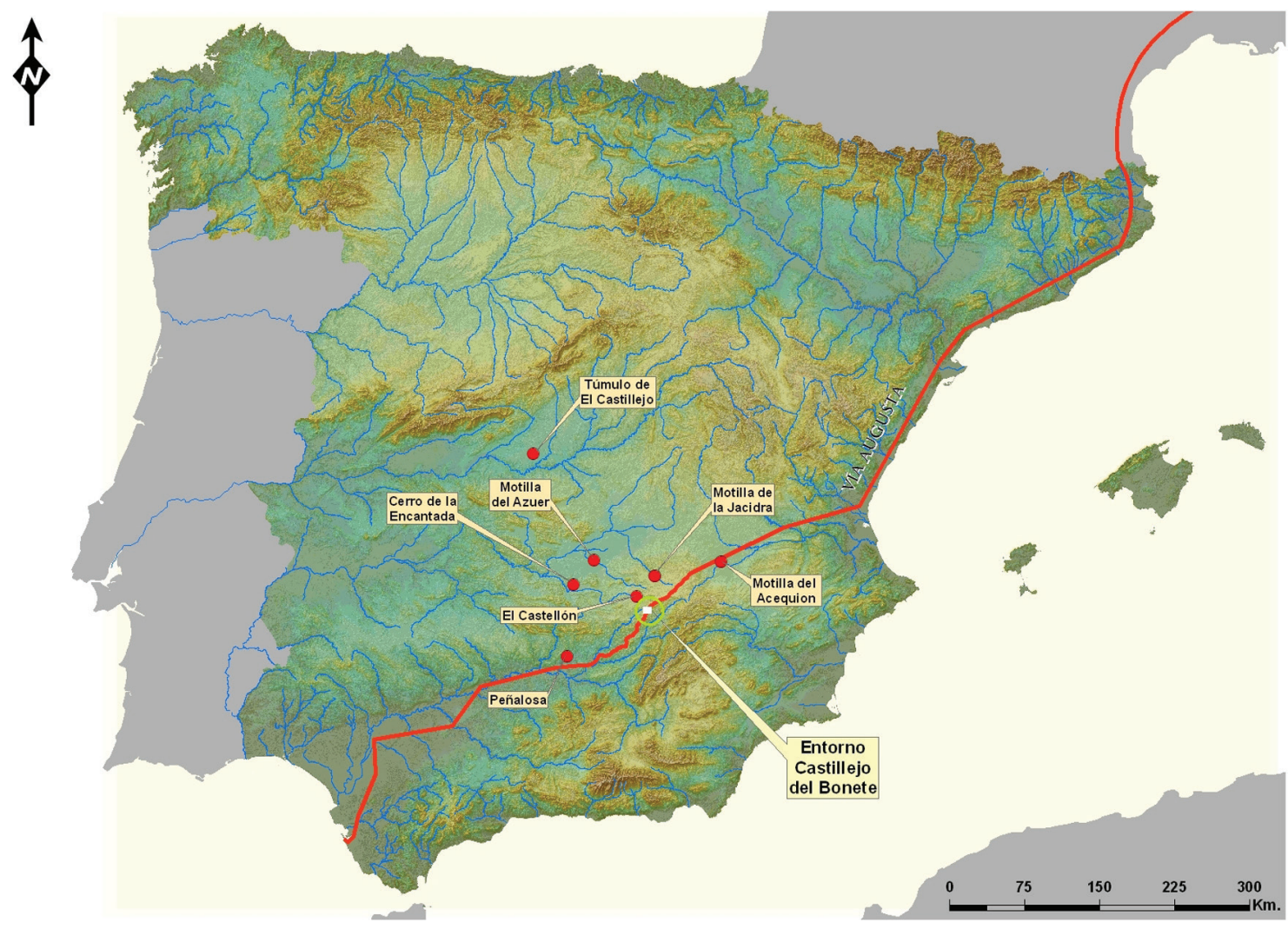

Fig. 1. Localización de Castillejo del Bonete y otros yacimientos publicados próximos. La línea en rojo señala el corredor natural de paso por el que en época romana discurrió la Vía Augusta. Dibujo: Jaime Moraleda Sierra. 


\section{Materiales}

Los materiales hallados en Castillejo del Bonete son buena muestra de la complejidad y singularidad de este yacimiento del interior peninsular. En el yacimiento se han recuperado 25 útiles de cobre en excelente estado de conservación (5 cuchillos o 6 flechas del tipo Palmela -no han aparecido flechas metálicas de otra clase- y numerosos punzones) mayoritariamente procedentes de las minas del área de Linares (Jaén) (Montero et al. 2014), 31 cuentas de varisicita o 3 preformatos de moscovita preparados para ser tallados, procedentes de diferentes minas. Hay adornos personales y numerosos punzones fabricados con hueso (Benítez de Lugo et al. 2014a, fig. 9), así como molinos barquiformes con su mano y solera en posición primaria, una maza ofítica (Benítez de Lugo et al. 2014a, fig. 8b) e industria lítica tallada, adscribibles a tradiciones calcolíticas del III milenio a.n.e. Se han encontrado cuatro botones de marfil (Benítez de Lugo et al. 2015) y restos de fauna consumida -posibles muestras de prácticas de comensalidad-, así como partes de animales depositadas enteras en el lugar; posiblemente ofrendas. Varios perros han sido enterrados en el yacimiento, pero no fueron consumidos como alimento. Numerosos huesos y fragmentos de hueso dispersos que fueron considerados inicialmente como fauna han resultado ser humanos. Algunos de ellos fueron enterrados bajo un panel con arte rupestre esquemático, situado en el interior de la cueva (Polo et al., 2015)..

Las dataciones absolutas de Castillejo del Bonete permiten fechar su uso entre el Cobre final y el Bronce Antiguo/Medio.

A continuación presentamos en detalle el estudio morfológico y tecnológico realizado sobre las piezas cerámicas recuperadas en la campaña de excavación de 2012. En primer lugar presentaremos los criterios de estudio, los materiales y su contexto arqueológico, para seguidamente exponer una interpretación de los análisis realizados.

\section{Objetivos: modelo de estudio}

Uno de los principales objetivos de la línea de investigación planteada desde 2003 es promover estudios y análisis que permitan obtener una lectura de los principales rasgos que definen a los componentes materiales, fundamentada en un tratamiento integral de la información.
En el caso del material cerámico se ha desarrollado un plan de trabajo estructurado en diferentes etapas, enfocadas a adquirir la información básica relacionada con la forma de las vasijas como unidad central de análisis, por una parte, y los datos de las variables tecnológicas consideradas en el estudio como elementos de análisis y contrastación, por otra (Vargas 1995).

Como punto de partida, la idea del trabajo es formular propuestas morfo-funcionales a través de los atributos contingentes de la forma y tamaño de las cerámicas. También se han considerado los aspectos tecnológicos y contextuales, como una suma de expresiones fenoménicas de la forma (Zedeño 1985). En este sentido nos pueden informar sobre las características del proceso laboral y de la capacidad productiva de la sociedad que generó las cerámicas, de su funcionalidad, manifestaciones simbólicas o distintivos formales y culturales (Aranda 2001).

A la hora de interpretar las relaciones entre productores y consumidores, y el modelo productivo, se han considerado el grado de especialización artesanal y el de estandarización de la producción. El primer concepto se puede entender como un sistema de producción regular, a tiempo parcial o completo, en el que los artesanos dependen, al menos en parte, de relaciones de intercambio de carácter supradoméstico, y en el que los consumidores necesitan adquirir los bienes de los productores; no obstante, para que la producción sea especializada es preciso que ambos no pertenezcan a la misma unidad doméstica (Costin, 2005). La estandarización expresa estos parámetros a través del rango de variabilidad de otros atributos: tecnológicos, morfológicos y/o estilísticos (Rice 1989; Fernández 2012). Así, cuanto más elevado sea el grado de homogeneidad estructural de un conjunto cerámico menos peso tendrá el número de unidades de producción $\mathrm{y}$, como resultado tanto la estandarización como la especialización de la producción serán mayores y viceversa (Aranda 2004).

Las variables incluidas en este estudio se han seleccionado a la luz de estos objetivos y planteamientos teóricos.

\section{Contextualización de la muestra cerámica}

Para el presente estudio se han seleccionado todos los lotes cerámicos recuperados durante la campaña de excavación de 2012. La cuantificación ha alcanzado un total de 3.198 fragmentos. De esta cantidad, se han descartado los amorfos, 


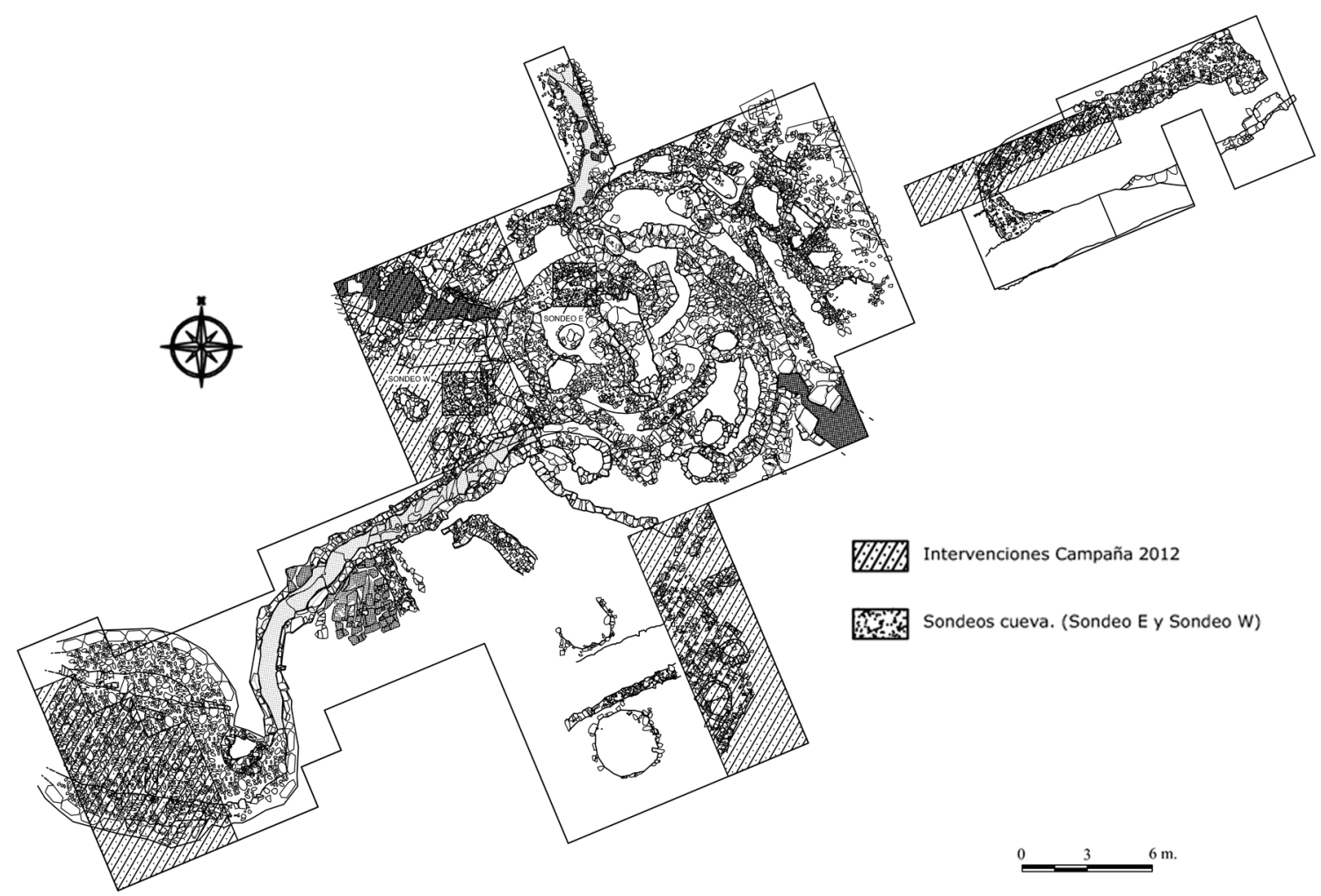

Fig. 2. Planta de Castillejo del Bonete. Áreas intervenidas en la campaña de 2012. Dibujo: Norberto Palomares y Enrique Mata.

quedando 494 fragmentos de selección, que posibilitan precisar su posición en la vasija o presentan algún elemento relevante de cara al estudio, $\mathrm{y}$ que han sido analizados.

Durante esta campaña fueron excavadas varias zonas (Fig. 2). La primera de ellas fue el interior de la cueva. Allí se abrieron dos sondeos de $4 \mathrm{~m}^{2}$ : el Sondeo Este y el Sondeo Oeste. El objetivo de ambos fue documentar la estratigrafía de la sima natural utilizada como cámara del Túmulo 1, en dos espacios separados e interesantes para el entendimiento de las características y los fenómenos erosivos sufridos en el interior de la cueva. De estos dos sondeos excavados dentro de la cueva proceden tres de las cuatro dataciones absolutas realizadas para Castillejo del Bonete (vid. infra). La segunda zona intervenida fue la zona oeste del Túmulo 1. Además se abrieron dos trincheras longitudinales de $2 \mathrm{~m}$ de ancho en la zona sur y este del Túmulo 1. Otra zona de actuación fue el Túmulo 2. Finalmente, se ha actuado sobre estructuras exhumadas en campañas anteriores, con el fin de realizar seis captaciones de muestras para datar lugares que resultan de interés para entender el funcionamiento del complejo tumular. Estas dataciones no se encuentran disponibles aún.

De las cuatro dataciones absolutas procedentes de Castillejo del Bonete dos fueron realizadas sobre hueso humano (Benítez de Lugo et al. 2014a) (Tabla 1). Otras dos, aún inéditas, se realizaron sobre restos vegetales carbonizados. Uno de ellos correspondía a un arbusto de vida corta (Rhamnus), mientras que la otra procedía de una encina o coscoja (Quercus ilex/cociffera). Estas cuatro fechas permiten saber que Castillejo del Bonete estuvo en uso entre mediados del tercer milenio y toda la primera mitad del segundo milenio.

La UE 26019 (Tabla 1) corresponde a un lugar de reducida capacidad situado en el extremo oeste de la sima natural, de difícil acceso, con una altura máxima de 1,4 $\mathrm{m}$ de altura, donde el ser humano no se sentiría cómodo para estar. El relleno estaba asociado a 31 cuentas de variscitas y, entre otros materiales, a varios fragmentos de cuencos, vasos carenados, ollas, cazuelas y alguna orza.

UE 26015 (Tabla 1): superficie con alto grado de buzamiento, más utilizada como zona de paso 


\begin{tabular}{|c|c|c|c|c|}
\hline $\begin{array}{l}\text { Castillejo } \\
\text { del Bonete }\end{array}$ & $\begin{array}{l}\text { Ref. } \\
\text { Lab }\end{array}$ & $\begin{array}{c}\text { Edad }^{14} \mathrm{C} \\
\text { BP }\end{array}$ & $\begin{array}{c}\text { cal BC } \\
(1 \sigma)\end{array}$ & cal BC $(2 \sigma)$ \\
\hline $\begin{array}{l}\text { Tumba } 4 \\
\text { (Fémur Ind. } \\
\text { 2) }\end{array}$ & $\begin{array}{c}\text { Rome- } \\
1687\end{array}$ & $\begin{array}{c}3720 \pm 70 \\
{ }^{14} \mathrm{C} \mathrm{BP}\end{array}$ & $\begin{array}{c}2271- \\
1984 \\
\text { calBC }\end{array}$ & $\begin{array}{c}2340-1921 \\
\text { calBC }\end{array}$ \\
\hline $\begin{array}{l}\text { Interior } \\
\text { cueva } \\
\text { (Falange } \\
\text { humana } \\
\text { TE12BO } \\
\text { UE260 19) } \\
\end{array}$ & $\begin{array}{c}\text { Beta- } \\
350768\end{array}$ & $\begin{array}{c}3870 \pm 30 \\
{ }^{14} \mathrm{C} \mathrm{BP}\end{array}$ & $\begin{array}{c}2454- \\
2293 \\
\text { calBC }\end{array}$ & $\begin{array}{c}2465-2211 \\
\text { calBC }\end{array}$ \\
\hline $\begin{array}{l}\text { Interior } \\
\text { cueva } \\
\text { (Quercus } \\
\text { ilex TE12BO } \\
\text { 26007) } \\
\end{array}$ & $\begin{array}{l}\text { Poz- } \\
67167\end{array}$ & $\begin{array}{c}3385 \pm 35 \\
{ }^{14} \mathrm{C} \mathrm{BP}\end{array}$ & $\begin{array}{c}1736- \\
1636 \\
\text { calBC }\end{array}$ & $\begin{array}{c}1769-1565 \\
\text { calBC }\end{array}$ \\
\hline $\begin{array}{l}\text { Interior } \\
\text { cueva } \\
\text { (Rhamnus } \\
\text { TE12BO } \\
\text { 26015) } \\
\end{array}$ & $\begin{array}{l}\text { Poz- } \\
67168\end{array}$ & $\begin{array}{c}3695 \pm 35 \\
{ }^{14} \mathrm{C} \mathrm{BP}\end{array}$ & $\begin{array}{c}2136- \\
2034 \\
\text { calBC }\end{array}$ & $\begin{array}{c}2199-1977 \\
\text { calBC }\end{array}$ \\
\hline
\end{tabular}

Tabla 1. Dataciones calibradas a partir de la datación estándar BP y su respectiva desviación típica a partir del programa OxCal 4.2beta, que trabaja con los datos de la curva INTCAL09 (Reimer et al., 2013).

hacia el interior de la cavidad natural que buza en la parte norte del sondeo este. Este estrato fue colmatado por un nivel de amortización que fue nivelado con posterioridad para crear la superficie de la hoguera de la UE 26007. El repertorio cerámico asociado a la UE 26015 es amplio, con cuencos, fuentes, vasos carenados, ollas y orzas.

UE 26007 (Tabla 1): pavimento con hoguera y alto grado de incendio que produjo una acumulación de cenizas mezcladas con restos arqueológicos. Este nivel de uso estaba nivelando la cueva, pero ha sido erosionado por dos paleocanales que han afectado a este y a otro nivel de uso inferior que tiene mayor buzamiento. Los restos cerámicos asociados en este caso pertenecen a dos vasos carenados, varios cuencos y distintos tipos de ollas.

\section{Estudio morfológico y tecnólogico del conjunto cerámico}

\subsection{Técnicas de análisis: el método}

En las últimas décadas se ha producido una tendencia a desarrollar estudios cerámicos de carácter local, con predilección por las clasificaciones tipológicas y por la aplicación de diferentes técnicas de ordenación, cuantificación y análisis del material. La incorporación del procesamiento informático y de técnicas estadísticas multiva- riantes ha generado un considerable número de publicaciones basadas en la aplicación de esta metodología (Contreras 1986; Lull y Micó 1999; Aranda 2001; Fernández 2012).

En nuestro caso, el principal propósito no es definir los tipos de la vajilla de Castillejo del Bonete, ni establecer una seriación taxonómica extensa. Por el momento, el trabajo se ha dirigido a ofrecer un retrato aproximado del repertorio formal documentado en la muestra que se ha tratado, y a recopilar otras evidencias que ayuden a comprender mejor la producción y uso de los recipientes del asentamiento.

El procedimiento que se ha empleado reproduce parcialmente el aplicado en otros trabajos anteriores (Fernández, 2012). En la toma de datos se han considerado toda una serie de variables morfológicas, tecnológicas y cualitativas, incluyendo catorce categorías, cuyos atributos han sido codificados, siguiendo el sistema confeccionado por el grupo de investigación del Departamento de Prehistoria y Arqueología de la Universidad de Granada GEPRAN. La información se ha adquirido mediante la observación macroscópica de los fragmentos cerámicos, el uso de lupas binoculares y de un microscopio estereoscópico Wild con condiciones de trabajo 10x. Cada fragmento y cada variable, por tanto, se han tratado a nivel individual, originando fichas que han sido incorporadas a una base de datos general. Con posterioridad, su procesamiento estadístico ha generado informes descriptivos y gráficos de frecuencias absolutas, porcentajes y resúmenes de casos, que han servido de base para la interpretación de los datos y su valoración final.

\subsection{Examen del repertorio formal}

La adscripción de cada fragmento a un determinado tipo formal se ha realizado valorando las formas preconocidas y calibrando, cuando ha sido posible, el tamaño, a través de la medición del diámetro de la boca, la carena o la altura del recipiente. La morfología de las vasijas, su denominación y su clasificación se han establecido desde una correlación con las formas típicas de la vajilla tradicional ibérica (vasos, cuencos, platos, fuentes, cazuelas, ollas, orzas, etc.). Otra serie de atributos formales, tecnológicos o dimensionales definen las alternativas que existen dentro de cada forma en concreto; sus variantes formales: plano (altura igual o menor que $1 / 3$ del diámetro de la boca), casquete esférico (altura igual o menor a $1 / 3$ del diámetro de la boca), semiesférico 
(altura igual o mayor que $1 / 3$ del diámetro de la boca y no supera los $2 / 3$ del diámetro de la boca), hondo o esférico (altura mayor a $2 / 3$ del diámetro de la boca), etc. y de tamaño (muy pequeño, pequeño, grande o muy grande). Estos criterios fueron establecidos por el grupo de investigación GEPRAN y se han ido modificando en función de los resultados obtenidos en análisis morfométricos realizados en diferentes trabajos (Contreras 1984, 1986; Contreras y Cámara 2000; Aranda 2001; Fernández 2005, 2008, 2012).

Una vez realizado el reconocimiento de los 494 fragmentos que incluye la muestra se ha realizado una primera clasificación básica distinguiendo formas simples y formas compuestas. Entendemos por formas simples: vasijas que no presentan ninguna inflexión, cambio brusco o ruptura en la tendencia de la pared, de modo que ofrecen un perfil sencillo continúo desde la base hasta el borde. Las formas compuestas son las vasijas en las que se pueden distinguir dos cuerpos, superior e inferior, que coinciden en un punto de unión, en el que la pared del recipiente cambia de dirección hasta llegar al fondo (Fernández, 2012:85, 94).

En una segunda clasificación formal ha sido posible distinguir la forma de 379 unidades, quedando organizadas de la siguiente manera:

Vasitos de pequeñas dimensiones (frecuencia: 4; porcentaje: $1,1 \%$ ):

-Vasito muy pequeño ovoide con cuello (frecuencia: 1 ; porcentaje: $0,3 \%$ ).

-Vasito ovoide (frecuencia: 3; porcentaje: $0,8 \%$ ).

El diámetro de la boca de los vasitos no supera los $90 \mathrm{~mm}$.

Vasos (frecuencia: 35; porcentaje: 9,2 \%):

-Vaso carenado, forma indeterminada (frecuencia 18; porcentaje: 4,7\%).

-Vaso carenado, carena media (frecuencia: 9; porcentaje: $2,4 \%$ ).

-Vaso carenado plano (frecuencia: 7; porcentaje: $1,8 \%$ ).

-Vaso de perfil en $\mathrm{S}$ suave (frecuencia: 1; porcentaje: $0,3 \%$ ).

Cuencos (frecuencia: 72; porcentaje: 19,2\%):

-Cuenco casquete esférico (frecuencia: 2; porcentaje: $0,5 \%$ ).

-Cuenco casquete esférico, borde ligeramente entrante (frecuencia: 1; porcentaje: $0,3 \%$ ).

-Cuenco elíptico (frecuencia: 2; porcentaje: $0,5 \%)$.

-Cuenco esférico (frecuencia: 1; porcentaje: $0,3 \%)$.
-Cuenco grande parabólico hondo (frecuencia: 1 ; porcentaje: $0,3 \%$ ).

-Cuenco grande semiesférico (frecuencia: 12; porcentaje: $3,2 \%$ ).

-Cuenco grande semiesférico, borde vertical (frecuencia: 3; porcentaje: 0,8\%).

-Cuenco grande semiesférico, borde ligeramente entrante (frecuencia: 1; porcentaje: $0,3 \%)$.

-Cuenco hondo (frecuencia: 1; porcentaje: $0,3 \%)$.

-Cuenco semiesférico (frecuencia: 27; porcentaje: $7,1 \%$ ).

-Cuenco semiesférico, borde ligeramente entrante (frecuencia: 3; porcentaje: 0,8 \%).

-Cuenco forma indeterminada (frecuencia: 17; porcentaje: $4,5 \%$ ).

-Escudilla (frecuencia: 1; porcentaje: 0,3\%).

Son grandes los cuencos que presentan un diámetro de la boca situado entre $160 \mathrm{~mm}$ y $220 \mathrm{~mm}$.

Fuentes (frecuencia: 32; porcentaje: 8,7\%):

-Fuente forma simple, borde vertical o ligeramente entrante (frecuencia: 1; porcentaje: $0,3 \%)$

-Fuente carenada (frecuencia: 1; porcentaje: $0,3 \%)$.

-Fuente casquete esférico (frecuencia: 4; porcentaje: $1,1 \%$ ).

-Fuente grande (frecuencia: 5; porcentaje: $1,4 \%)$.

-Fuente forma simple (frecuencia: 1 ; porcentaje: $0,3 \%)$.

-Fuente honda semiesférica (frecuencia: 20; porcentaje: $5,3 \%$ ).

Los rangos establecidos para el tamaño de las fuentes, parten de un diámetro de la boca superior a $220 \mathrm{~mm}$. A partir de $300 \mathrm{~mm}$ las fuentes son clasificadas como grandes.

Platos (frecuencia: 3; porcentaje: 0,9\%):

-Plato forma simple, borde biselado (frecuencia: 1 ; porcentaje: $0,3 \%$ ).

-Plato forma simple (frecuencia: 1; porcentaje: $0,3 \%)$.

-Plato hondo forma simple y fondo plano (frecuencia: 1; porcentaje: 0,3\%).

Cazuelas (frecuencia: 7; porcentaje: 1,8\%):

-Cazuela carenada (frecuencia: 5 ; porcentaje: $1,3 \%$ ).

-Cazuela carenada grande (frecuencia: 2; porcentaje: $0,5 \%$ ).

Se denomina como cazuela carenada grande, a la que presenta un diámetro de la boca superior a $240 \mathrm{~mm}$. 
Botellas (frecuencia: 3; porcentaje: 0,8 \%): -Botella grande (frecuencia: 3; porcentaje: $0,8 \%)$.

Ollas (frecuencia: 143; porcentaje: $38 \%$ ): -Olla carenada grande (frecuencia: 1; porcentaje: $0,3 \%$ ).

-Olla globular grande, cuello indicado (frecuencia: 4; porcentaje: $1,1 \%$ ).

-Olla globular, cuello indicado (frecuencia: 8; porcentaje: $2,1 \%$ ).

-Olla globular (frecuencia: 8; porcentaje: 2,1\%). -Olla globular, cuello marcado y borde abierto (frecuencia: 3; porcentaje: 0,8 \%).

-Olla forma indeterminada (frecuencia: 40; porcentaje: $10,6 \%$ ).

-Olla ovoide, paredes abiertas (frecuencia: 1 ; porcentaje: $0,3 \%$ ).

-Olla ovoide plana, cuello indicado (frecuencia: 1 ; porcentaje: $0,3 \%$ ).

-Olla ovoide, borde entrante (frecuencia: 8; porcentaje: $2,1 \%$ ).

-Olla ovoide plana, grandes dimensiones (frecuencia: 1; porcentaje: 0,3\%).

-Olla ovoide, cuello indicado (frecuencia: 23; porcentaje: $6,1 \%$ ).

-Olla ovoide (frecuencia: 39; porcentaje: $10,3 \%)$.

-Olla ovoide pequeña, cuello indicado (frecuencia: 6 ; porcentaje: $1,6 \%$ ).

En ollas ovoides simples son clasificadas como pequeñas: diámetro de la boca menor de $140 \mathrm{~mm}$; medianas: diámetro de la boca entre $160 \mathrm{~mm}$ y 220 $\mathrm{mm}$; grandes: diámetro de la boca superior a 220 $\mathrm{mm}$. En ollas ovoides y globulares con cuello o carenadas son designadas pequeñas: diámetro de la boca menor de $140 \mathrm{~mm}$; medianas: diámetro de la boca entre $140 \mathrm{~mm}$ y $170 \mathrm{~mm}$; grandes: diámetro de la boca entre 170 y $240 \mathrm{~mm}$; grandes dimensiones: diámetro de la boca de más de $240 \mathrm{~mm}$.

Orzas (frecuencia: 68; porcentaje: 17,9\%):

-Orza carenada (frecuencia: 4; porcentaje: 1,1\%). -Orza ovoide, cuello marcado y borde ligeramente abierto (frecuencia: 22; porcentaje: $5,8 \%$ ).

-Orza globular, cuello marcado (frecuencia: 2 ; porcentaje: $0,5 \%$ ).

-Orza ovoide (frecuencia: 5; porcentaje: 1,3\%). -Orza forma indeterminada (frecuencia: 35 ; porcentaje: 9,2\%).

Otros (frecuencia: 12; porcentaje: 3,1\%): -Quesera (frecuencia: 2; porcentaje: 0,5\%). -Fragmento recortado sin perforación (frecuencia: 10 ; porcentaje: $2,6 \%$ ).
En los 115 casos restantes que componen la muestra solo ha sido posible definir la posición del fragmento en el perfil de la vasija y su dirección o tendencia formal:

\section{Otras claves morfológicas (OCMO)}

-Selección de forma no identificable (frecuencia: 13).

-Borde curvo saliente (frecuencia: 61).

-Borde curvo entrante (frecuencia: 8).

-Borde recto saliente (frecuencia: 8).

-Borde recto vertical (frecuencia: 16).

-Fondo-ónfalo o umbilicado (frecuencia: 1).

-Fondo plano (frecuencia: 1).

-Fondo rehundido/cóncavo (frecuencia: 1).

-Galbo carenado (6).

El diagnóstico más elemental del conjunto cerámico marca un número de ejemplares de formas abiertas y cerradas prácticamente parejo. En otro estadio básico de clasificación, las formas simples, con un porcentaje del $39,8 \%$, son algo inferiores en número a las formas compuestas, que suponen un $60,2 \%$ del total.

Por otro lado el grupo mejor representado en cuanto a cantidad de unidades y variedad formal es el de las ollas (Fig. 3: 1-4; 7-10) (Fig. 4: 11, 12) (Fig. 5: 25-27) en donde se encuentran el

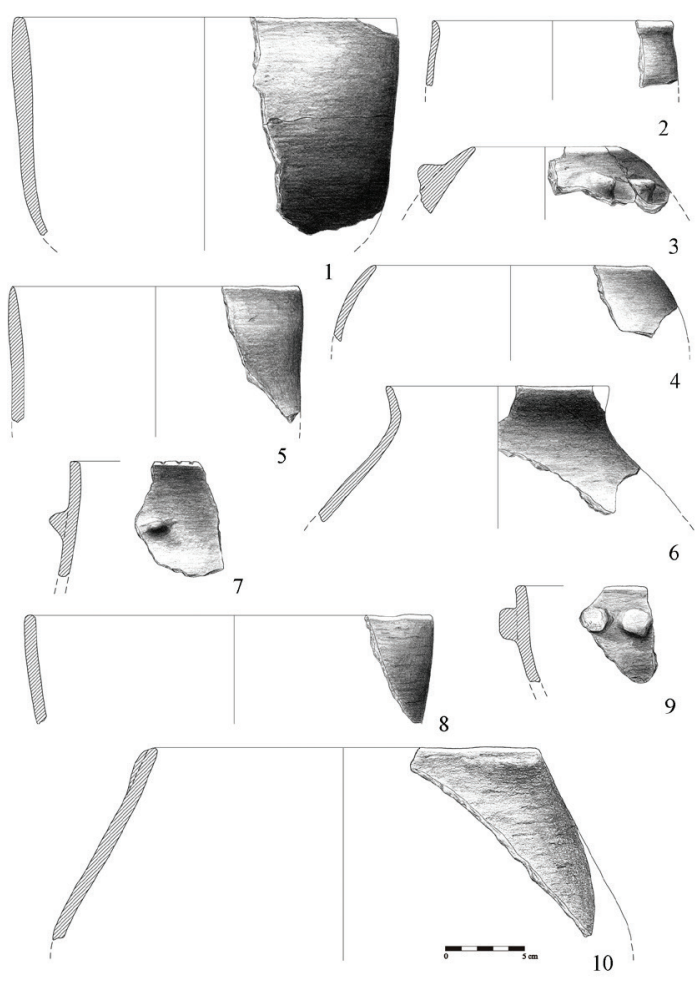

Fig. 3. Diferentes tipos de ollas y botellas. 


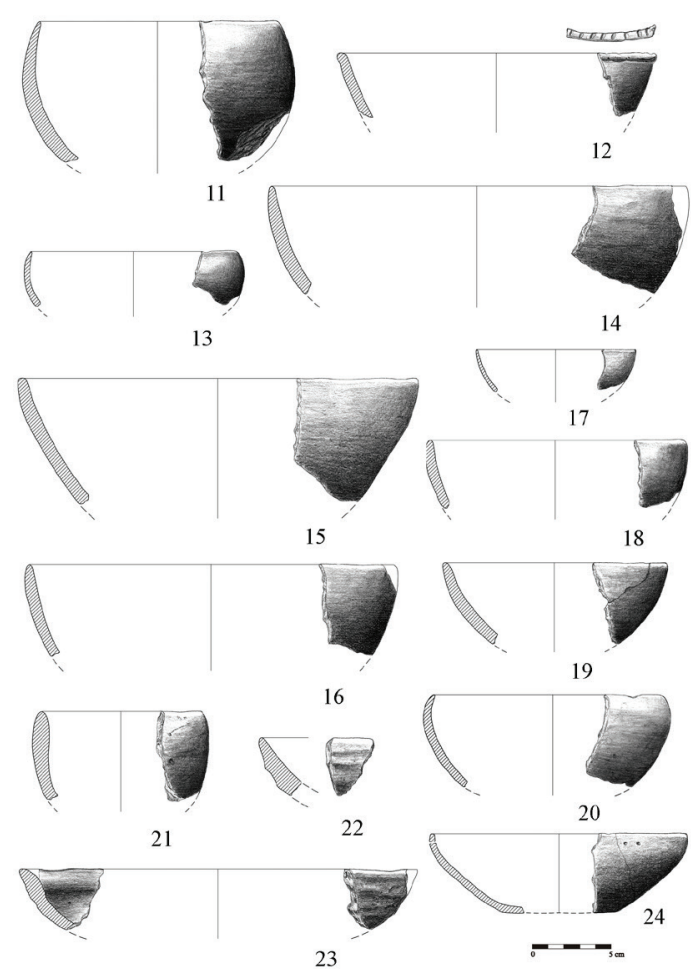

Fig. 4. Representación de cuencos, Fuentes, platos y ollas ovoides simples.

$38 \%$ de los recipientes incluidos en el estudio. Dentro de este conjunto localizamos el tipo cerámico más abundante: las ollas ovoides simples, con 39 unidades (Fig. 3: 1, 8, 9) (Fig. 4: 11, 12). También se han documentado formas globulares de bocas más o menos cerradas (Fig. 3: 3, 4) y compuestas con el cuerpo inferior ovoide o globular, cuello indicado o marcado y borde más o menos saliente (Fig.3: 2, 7) además de un fragmento perteneciente a una olla carenada.

En el grupo de cuencos (Fig. 4: 13, 17-21), que sigue en número al anterior con casi el $20 \%$ de individuos, predominan ampliamente los de forma semiesférica, incluyendo todo el repertorio de tamaños (Fig. 4: 17-19). Las alternativas formales, como ocurre en los de casquete esférico (Fig. 4: 13), vienen determinadas también por la tendencia del borde, que puede ser saliente, vertical o entrante. Menos corrientes son los cuencos hondos (Fig. 4: 21), los de pared con tendencia parabólica y elíptica (Fig. 4: 20) o el único ejemplar de escudilla registrado, como la vasija más plana del conjunto. Las fuentes (Fig. 4: 14-16), siguen los patrones morfológicos de los cuencos, si bien, se percibe una disparidad evidente en el

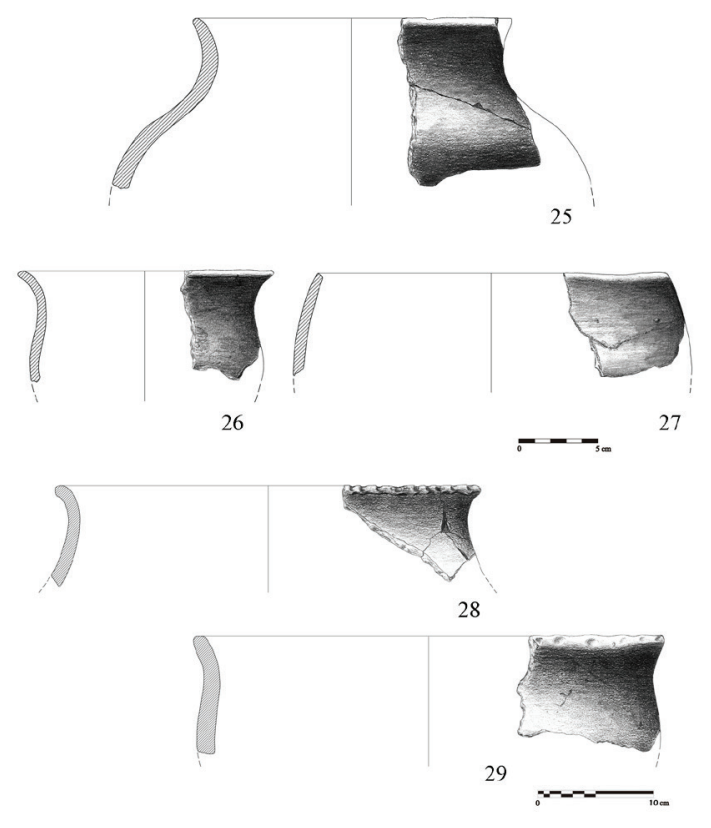

Fig. 5. Ollas y orzas.

grosor de las paredes, pudiendo encontrar fuentes con paredes finas y tratamientos cuidados, y otras de similares dimensiones y forma, con paredes gruesas, asociadas a tratamientos más toscos. También se ha localizado un ejemplar carenado con la carena muy alta, marcando un hombro al exterior.

La vajilla de almacenaje compuesta por las orzas aglutina un 17,9\% del complejo cerámico analizado (Fig.5: 28, 29). Se han identificado cinco clases formales diferentes, destacando las orzas ovoides con el cuello marcado y el borde ligeramente abierto, que es el tipo de contenedor de almacenamiento más extendido en los yacimientos manchegos durante la Edad del Bronce y que está bien documentado en asentamientos representativos de este horizonte como la Motilla del Azuer (Daimiel, Ciudad Real) (Nájera 1982; Fernández 2012) o el Cerro de la Encantada (Granátula de Calatrava, Ciudad Real) (Nieto y Sánchez, 1980; Sánchez, 1994), entre otros. Con independencia de este patrón morfológico, en Castillejo existen grandes contenedores de forma ovoide simple, con el cuerpo inferior globular y cuello marcado (Fig.5: 29) y carenados.

Con la salvedad de un ejemplar de perfil en $\mathrm{S}$, todos los demás vasos son carenados (Fig. 6: 3237 ). Los hay con carenas a media altura y proporciones equilibradas entre el diámetro de la boca y la altura (Fig. 6: 33,34), y aplanados (Fig. 6: 


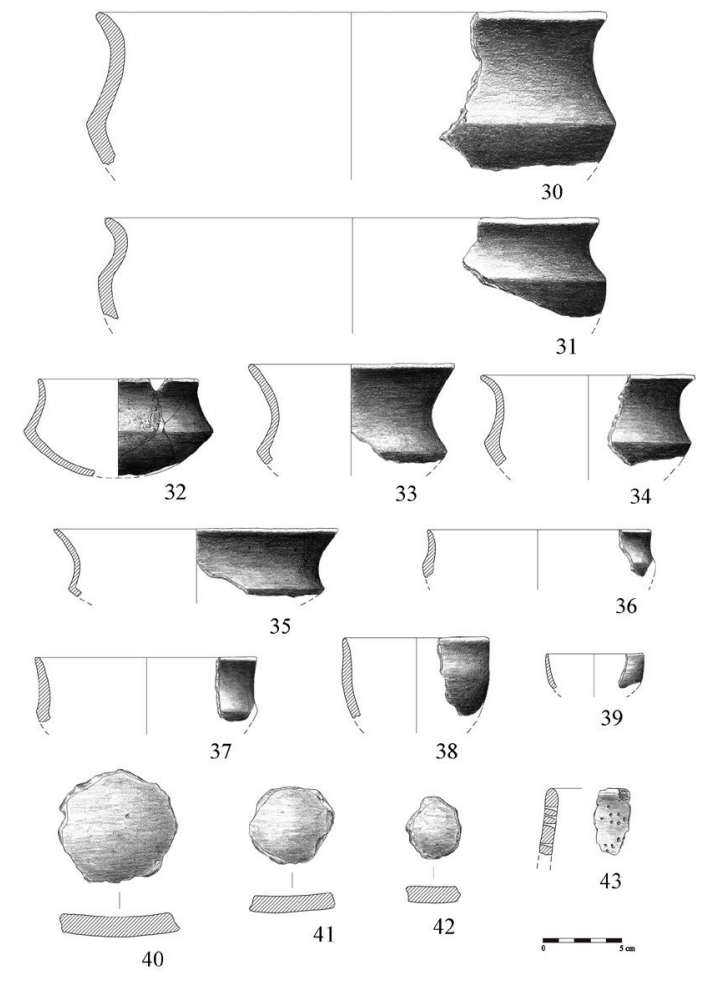

Fig. 6. Formas carenadas, vasitos, fichas recortadas y quesera.

35,37). En la mayor parte de los casos, las paredes son finas y las carenas se encuentran definidas al exterior. Nos parece oportuno hacer notar que los vasos carenados sólo constituyen el 8,9\% del material examinado y que el total de formas carenadas suma apenas un 10,3\%, mientras que en yacimientos como la Motilla del Azuer, los estudios realizados demuestran que los porcentajes de vasijas carenadas alcanzan algo más del $40 \%$ (Fernández, 2012: 95).

Las cazuelas carenadas (Fig. 6: 30, 31), con 7 fragmentos reconocidos, son el siguiente estadio volumétrico de las formas carenadas, tras los vasos. En algunos casos alcanzan diámetros de la boca que superan los $300 \mathrm{~mm}$.

Los recipientes de menor tamaño, son 4 vasitos ovoides (Fig. 6: 38, 39), uno de ellos con cuello (Fig. 6: 38). Ninguno supera los $90 \mathrm{~mm}$ de diámetro de la boca. Todos tienen las paredes finas.

Menos presentes aún están los platos $(0,9 \%)$ (Fig. 4: 22-24). Dos ejemplares manifiestan atributos asociados a los tipos del Calcolítico, como las paredes gruesas, en un caso, o el borde almen- drado, bisel interno, superficie interior más cuidada que la exterior, incluyendo la impronta del molde en esta última, en otro de los platos (Fig. 4: 22, 23).

Finalmente, dentro de las formas especiales, también se han documentado la pared y el borde de dos queseras (Fig. 6: 43), con las características propias de estos elementos en yacimientos coetáneos, así como 10 fragmentos recortados circulares (Fig. 6: 40-42) como únicos elementos reciclados a partir de la cerámica del monumento. Entre los atributos secundarios debemos destacar la gran cantidad de labios aplanados que incluye el conjunto.

\subsection{Variables tecnológicas y cualitativas:}

\subsubsection{Tratamiento de la superficie}

Las categorías que se han establecido para clasificar los tratamientos de superficie son: alisado (A), bruñido (B) y pulido (P). Se pueden definir como tres grados de la textura de la superficie, conseguidos mediante el frotado con una herramienta lisa cuando la cerámica alcanza el estado de textura de cuero. Las diferencias entre los tres estados son de grado. El alisado (grado bajo) supone una textura más o menos regular. El pulido (grado medio) muestra superficies sin lustre, con textura mate, debido al tipo de instrumentos usados para frotar la superficie. El bruñido (grado alto), por su parte, supone un lustre de la superficie, además del cierre de los poros de la pared. No hemos incluido el espatulado, al considerarlo como un estadio primario o básico del bruñido (Fernández 2012: 68).

El alisado sobresale como principal técnica de tratamiento de superficie, con el $60 \%$ de los casos, doblando en número al bruñido, que se aplicó a un tercio de la muestra. El pulido, por el contrario solo se ha documentado en seis vasijas. En algunos casos (trece fragmentos) no se ha podido identificar el tratamiento de superficie debido a que las concreciones cubrían ambas superficies (X) (Fig. 7).

Si distinguimos por formas, existe una clara asociación del alisado a la vajilla de cocina y almacenamiento. En torno al $80 \%$ de las superficies de las ollas se regularizaron aplicando esta técnica. El porcentaje se acrecienta en las ollas ovoides, en las que supera el $90 \%$. Las cifras se invierten radicalmente en el grupo de los vasos, y todos los que se han incluido en el estudio están bruñidos, como sucede en las cazuelas carenadas 


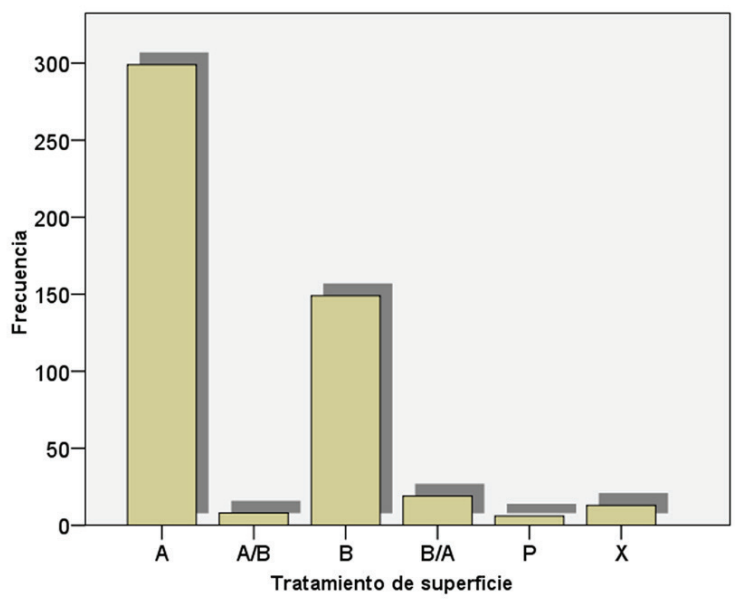

Fig. 7. Representación de los casos en la variable tratamiento de superficie. A (alisado); B (bruñido); P (pulido); A/B (exterior alisado/interior bruñido); $\mathrm{B} / \mathrm{A}$ (exterior bruñido/interior alisado); X (sin identificar).

de mediano tamaño. En los cuencos, sin embargo, no se detecta preferencia por ninguno de los dos tratamientos, y en las fuentes el alisado predomina ligeramente sobre el bruñido. La mayoría de vasitos de pequeñas dimensiones se alisaron, habiendo conseguido para estos superficies muy lisas y uniformes. Por lo demás, las dos botellas (Fig. 3: 5, 6) y dos de los tres platos también se trataron alisando ambas caras (Fig. 4: 22, 23).

Cuando la superficie externa está bruñida y la interna alisada (B/A), se explica por la mayor dificultad de bruñir el interior, sobre todo en el caso de formas cerradas, en las que se produce esta circunstancia con mayor frecuencia. Además en la cara interna se apreciaría menos la calidad de la terminación. Existen menos casos que reproduzcan el efecto contrario (A/B), y para los que no hemos encontrado ninguna explicación convincente.

Por otro lado, los trazos de arrastre apreciados en la superficie de diferentes recipientes implican el uso de instrumentos confeccionadas con vegetales de tallo fino y de otras herramientas de pequeña anchura (Fig. 8). En otros casos sencillamente ha quedado marcado el arrastre de los dedos en diferentes posiciones a lo largo de la pared.

En definitiva, los resultados ponen de manifiesto una relación obvia entre los acabados de las superficies de las vasijas y su forma, como es habitual en los conjuntos de cerámica prehistórica. En el caso de Castillejo del Bonete, la preferencia por acabados más elaborados se aprecia en los vasos carenados, especialmente en uno de

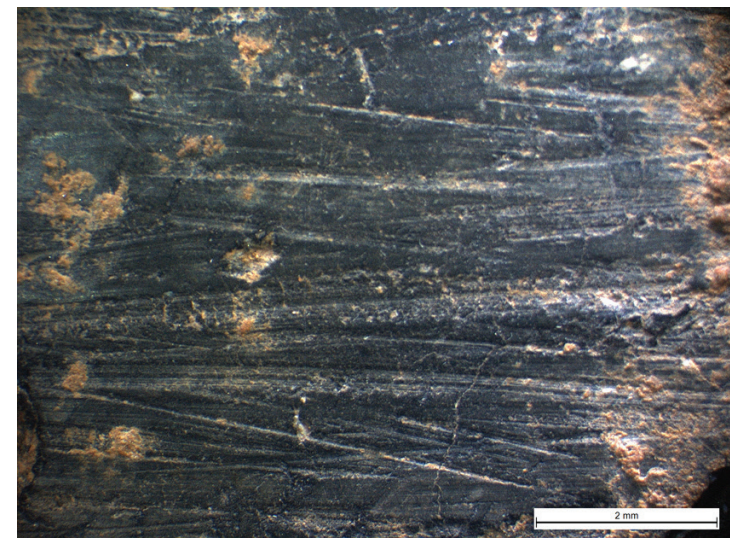

Fig. 8. Trazos dejados por instrumento con fibras finas al alisar la superficie.

los tipos con carena media, borde poco saliente y labio aplanado, pudiendo encontrar bruñidos intensos de las superficies (Fig. 6: 32).

\subsubsection{Color de la superficie}

En esta variable se describe el color principal en primer lugar, seguido del color secundario en caso de haberlo, señalado con la segunda letra del código. Por último se indica la tonalidad. En algunos casos no se ha podido determinar el color, porque las concreciones cubren toda la superficie (X). Se ha definido una escala con la gama de

\begin{tabular}{|l|l|l|}
\hline \multicolumn{1}{|l|}{ Color } & Código Munsell & Tonalidad \\
\hline Amarillento (A) & 2,5 Y 7/6 & Claro \\
Beige (B) & 7,5 YR 7/4 & Medio \\
Beige-amarillento & 10 YR 7/6 & Oscuro \\
(BA) & 10 YR 6/2 & \\
Beige-grisáceo (BG) & 7,5 R 5/3 & \\
Beige-rojizo (BR) & 5 Y 2/1 & \\
Negro (E) & 7,5 Y 5/1 & \\
Gris (G) & 10 R 4/2 \\
Gris-rojizo (GR) & 5 YR 7/8 \\
Anaranjado (N) & 2,5 Y 6/8 & \\
Pardo-beige (PB) & 2,5 Y 5/3 & \\
Pardo-grisáceo (PG) & 2,5 Y 4/4 & \\
Pardo-rojizo (PR) & 10 R 4/8 & \\
Rojizo & & \\
\hline
\end{tabular}

Tabla 2. Gama de colores utilizada en el análisis de las muestras incluyendo el código Munsell asociado y los rangos de tonalidad considerados. 


\begin{tabular}{|l|r|r|}
\hline $\begin{array}{l}\text { Color } \\
\text { sup. } \\
\text { interna }\end{array}$ & $\begin{array}{c}\text { Fre- } \\
\text { cuencia }\end{array}$ & $\begin{array}{l}\text { Porcen- } \\
\text { taje }\end{array}$ \\
\hline BAC & 9 & 1,8 \\
\hline BC & 25 & 5,1 \\
\hline BGC & 19 & 3,8 \\
\hline BGM & 10 & 2,0 \\
\hline BM & 1 &, 2 \\
\hline BRC & 5 & 1,0 \\
\hline BRM & 4 &, 8 \\
\hline E & 48 & 9,7 \\
\hline GC & 8 & 1,6 \\
\hline GM & 25 & 5,1 \\
\hline GO & 110 & 22,3 \\
\hline GRM & 2 &, 4 \\
\hline GRO & 1 &, 2 \\
\hline NC & 42 & 8,5 \\
\hline NM & 3 &, 6 \\
\hline PBC & 3 &, 6 \\
\hline PBM & 3 &, 6 \\
\hline PGM & 28 & 5,7 \\
\hline PGO & 42 & 8,5 \\
\hline PRC & 1 &, 2 \\
\hline PRM & 53 & 10,7 \\
\hline PRO & 17 & 3,4 \\
\hline RC & 2 &, 4 \\
\hline RM & 26 & 5,3 \\
\hline X & 7 & 1,4 \\
\hline Total & 494 & 100,0 \\
\hline & & \\
\hline
\end{tabular}

\begin{tabular}{|l|r|r|}
\hline $\begin{array}{l}\text { Color } \\
\text { sup. } \\
\text { externa }\end{array}$ & $\begin{array}{c}\text { Fre- } \\
\text { cuencia }\end{array}$ & $\begin{array}{l}\text { Porcen- } \\
\text { taje }\end{array}$ \\
\hline BAC & 9 & 1,8 \\
\hline BC & 27 & 5,5 \\
\hline BGC & 20 & 4,0 \\
\hline BGM & 10 & 2,0 \\
\hline BRC & 12 & 2,4 \\
\hline BRM & 3 &, 6 \\
\hline E & 28 & 5,7 \\
\hline GC & 13 & 2,6 \\
\hline GM & 24 & 4,9 \\
\hline GO & 56 & 11,3 \\
\hline GRC & 1 &, 2 \\
\hline GRM & 2 &, 4 \\
\hline GRO & 1 &, 2 \\
\hline NC & 48 & 9,7 \\
\hline NM & 3 &, 6 \\
\hline PBC & 3 &, 6 \\
\hline PBM & 7 & 1,4 \\
\hline PGM & 32 & 6,5 \\
\hline PGO & 38 & 7,7 \\
\hline PRC & 1 &, 2 \\
\hline PRM & 64 & 13,0 \\
\hline PRO & 36 & 7,3 \\
\hline RC & 2 &, 4 \\
\hline RM & 45 & 9,1 \\
\hline X & 9 & 1,8 \\
\hline Total & 494 & 100,0 \\
\hline & & \\
\hline
\end{tabular}

Tabla 3. Gama cromática y tonalidad documentadas en la muestra.

colores básicos que suelen aparecer en las cerámicas prehistóricas analizadas y que son los siguientes: (Tabla 2).

En general, las cerámicas tienen las manchas y coloraciones poco uniformes que producen las cocciones con estructura sin cámara, en las que las cerámicas están en contacto con el combustible y que están originadas por la oscilación en la proyección directa del fuego, así como por la variabilidad localizada de los gases y el tipo de atmósfera. No obstante, los datos muestran que predominan los colores grisáceos y pardo-grisáceos, seguidos de los pardo-rojizos, el negro, los anaranjados y beige (Tabla 3).

En la superficie externa hay poca diferencia entre la cantidad de vasijas que presentan tonos claros, medios u oscuros, mientras que en la interna tienen más peso los oscuros. En los análisis pormenorizados por formas se ha detectado cierta tendencia de ollas y orzas a tener el interior oscuro, cuestión que debe estar relacionada con su tamaño y su forma cerrada y profunda, que difi- cultaría la entrada de oxígeno durante la cochura. También puede deberse a la posición que adoptarían algunos tipos cerámicos durante este proceso y que habrían producido el mismo efecto de haberse colocado bocabajo. De cualquier manera, nos inclinamos por la primera hipótesis, puesto que los resultados a este respecto no son determinantes, ni tan representativos, como lo son en otros yacimientos, como la Motilla del Azuer, en los que se ha llevado a cabo la misma comparativa (Fernández, 2012:70). Otro tipo formal en el que se puede establecer un vínculo forma-colortonalidad es en los vasos carenados. En este caso a la preferencia por los acabados más elaborados, como el bruñido, se une una mayor presencia de superficies de color gris, pardo grisáceo y negro, unidos a tonos oscuros, probablemente porque se persiguiese conseguir esta gama cromática en la que el brillo del bruñido destaca más y puede ser más atractivo estéticamente .

\subsubsection{Color de la sección}

Con esta variable, comenzamos con la descripción de los atributos que definen a la matriz. Para determinar la coloración interna de la pasta tras su cocción se han definido 9 categorías cromáticas:

A: Color uniforme. Tonalidad clara. Desde beige y amarillento hasta anaranjado.

B: Color uniforme. Tonalidad media y oscura. Desde rojizo a pardo oscuro.

C: Color uniforme. Tonalidad media y oscura. Desde gris a negro.

D: Núcleo desde rojizo a pardo oscuro y filetes o bandas ${ }^{1}$ [más claros.

E: Núcleo desde gris a negro y filetes o bandas más claros.

F: Dos bandas, una de ellas en la gama de colores que va desde el rojizo al pardo oscuro.

G: Dos bandas, una de ellas en la gama de colores que va desde el gris al negro

$\mathrm{H}$ : Dos bandas, una de ellas en la gama que va desde el rojizo al pardo oscuro y la otra desde el gris al negro.

I: Núcleo desde rojizo a pardo oscuro y filetes o bandas más oscuros.

Si estructuramos los resultados obtenidos (Fig. 9), comprobaremos que algo más de la mitad de los individuos estudiados tiene una colora- 


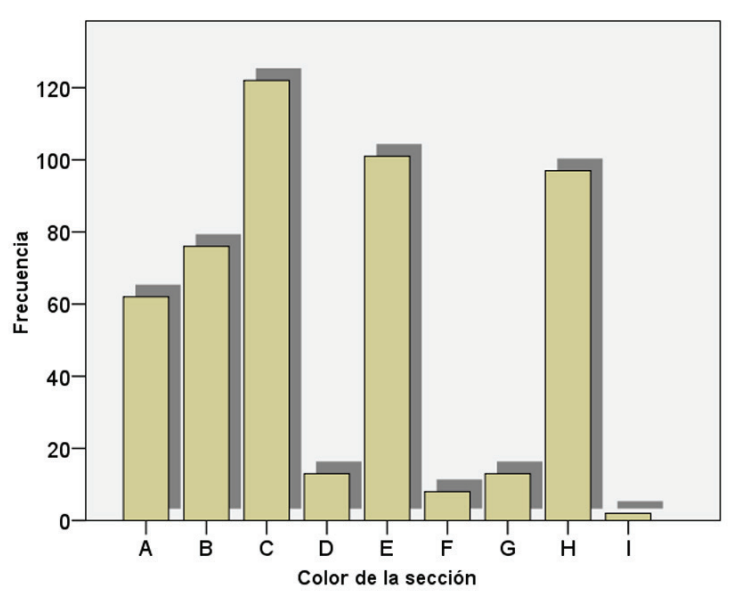

Fig. 9. Frecuencia de los diferentes tipos de coloración de la matriz.

ción de la sección uniforme (A, B, C). Un 23,8\% presenta dos bandas (F, G, y H), y un $23,4 \%$ se caracteriza por tener un núcleo comprendido por dos bandas o filetes diferentes (D, E, I). Sobresalen, por tanto, los fragmentos cuya fábrica está caracterizada por una o dos fases.

En lo que respecta a los colores y tonalidades, los más representados son los grisáceos y los tonos oscuros, atribuidos a cocciones reductoras. Ello no quita que las coloraciones rojizas y los tonos medios, adscritos a cocciones oxidantes, no estén bien significados. Si descomponemos la muestra por formas y la conectamos con las categorías de color de sección, solamente encontramos cierta asociación de los vasos carenados con la $\mathrm{C}$ y la $\mathrm{E}$, distinguidas por el predominio del gris oscuro en toda la matriz o en el núcleo. Esta circunstancia concuerda con el predominio superficial de coloraciones grisáceas y tonos oscuros detectada en el conjunto de vasos carenados, y que vendría a corroborar una estrategia de cocción diferente para esta forma en concreto. Nuestra hipótesis es que se sometería a estas formas con acabados más elaborados a ambientes reductores para conseguir los distintivos estéticos que los caracterizan y separan del resto de la vajilla. Del resto de tipos formales no se puede extraer ninguna inferencia importante más.

\subsubsection{Compacidad de la matriz}

Con relación al grado de compacidad de la pasta se han distinguido tres niveles en base a la resistencia mecánica de la matriz cerámica al contacto y ligero raspado con un elemento metálico, así como al nivel de desprendimiento de las inclusiones. Consideramos compacta a la matriz en la que prácticamente no hay desprendimiento de material (menos de un $15 \%$ ), media a la que se desprende entre un $15 \%$ y un $50 \%$ del material, y poco compacta a aquella en la que se desprende más de un $50 \%$ del material.

La amplia mayoría de las matrices $(92,7 \%)$ tienen un grado de compacidad medio, siendo bastantes menos las poco compactas $(6,3 \%)$ y raras las compactas $(1 \%)$. Como se desprende de los resultados, las de compacidad media abarcan todo tipo de formas y la representación de las compactas no es suficiente como para señalar ninguna correlación formal. Por el contrario, las poco compactas corresponden en un $74 \%$ a ollas y orzas e incluyen un alto contenido de partículas gruesas, estando muy presentes en los contextos regionales de la Edad del Bronce. Esto no quiere decir que todas las ollas y orzas del conjunto examinado posean estás cualidades, puesto que, en realidad, sólo una décima parte de la vajilla de cocina y almacenaje las tiene.

Por lo general, las pastas con un alto contenido de inclusiones facilitan el levantamiento de la pared de las vasijas durante su fabricación, sobre todo en el caso de contenedores de gran tamaño. Además las paredes son más porosas y muestran una mayor transpiración de cara a su uso como elementos de cocina (evapotranspiración), o en la conservación de alimentos líquidos o sólidos durante su almacenamiento.

\subsubsection{Tamaño de las inclusiones}

En base al predominio de un determinado tamaño de desgrasante se han designado tres categorías: pequeño, con un diámetro de las partículas de menos de $1 \mathrm{~mm}$; mediano, con un diámetro comprendido entre $1 \mathrm{~mm}$ y $3 \mathrm{~mm}$; y grueso, con un diámetro mayor de $3 \mathrm{~mm}$.

En un $52,2 \%$ de las cerámicas dominan los de pequeño tamaño, en un 30,4\% los de medianas dimensiones, en un $16,4 \%$ los gruesos y un $1 \%$ no presenta inclusiones. Como cabía esperar, las matrices que incluyen mayor cantidad de partículas gruesas son las de las vasijas de mayor volumen, como orzas y ollas. Solamente las ollas ovoides y algunas orzas con pastas claras y poco cocidas, que contienen principalmente desgrasantes de pequeño y mediano tamaño escapan a esta situación. Los de mediano tamaño se reparten indistintamente entre todo el repertorio de formas. En cambio los recipientes de menor 
volumen, como vasos, vasitos y cuencos, acaparan las pastas con predominio de desgrasantes de pequeño tamaño.

Por lo tanto existe una relación entre el tamaño de las inclusiones y las vasijas que tiene que ver en primer lugar con el proceso de manufactura y el tamaño de los recipientes. Resulta evidente que, cuanto mayor es el grosor de una pared, mayor es el tamaño de las partículas que admite. Otra cuestión distinta es la causa de este reparto, que está conectado con la variable anterior y con la siguiente y que tiene que ver, como se explicará en las conclusiones, con la adecuación entre la fabricación de las piezas y su función.

\subsubsection{Cantidad de desgrasante}

Con esta variable terminamos con los apartados dedicados a la descripción de la matriz. En este caso, se refiere a la cantidad del desgrasante, que se ha determinado basándonos en el sistema gráfico y porcentajes de estimación creados por Mathew, Woods y Oliver (1991), partiendo de cinco niveles (Fig.10):

-Sin inclusiones (S) (Menos de $5 \%$ ).

-Muy escasos (C) (5\%).

-Escasos (E) (10\%).

-Cantidad media (M) (20\%).

-Abundantes (A) (30\%).

-Muy abundantes (B) (más de 30\%).

Las matrices más normalizadas son aquellas que contienen una cantidad media $(38,3 \%$ de los casos) o escasa (33\% de los casos) de desgrasante, seguidas por las que presentan una proporción abundante (16,2\% de los casos), muy escasa ( $8,5 \%$ de los casos), muy abundante $(2,8 \%$ de los casos), y por último las que no tienen desgrasante añadido (1,2\% de los casos). En lo que respecta a las formas, la cantidad de desgrasante es similar en vasos, cuencos y fuentes, en las que se sitúa entre escasa y media. En las ollas y orzas sobresalen las matrices con cantidad media o abundante, mientras que en cazuelas y resto de formas pueden aparecer distintas proporciones sin que prevalezca ninguna.

Estas diferencias de inclusiones en el repertorio cerámico concuerdan con las variables anteriores y atestiguan un control de las proporciones de antiplásticos añadidos durante la preparación de las pastas, anticipándose al tipo de vasija que se iba a fabricar y también a su función.

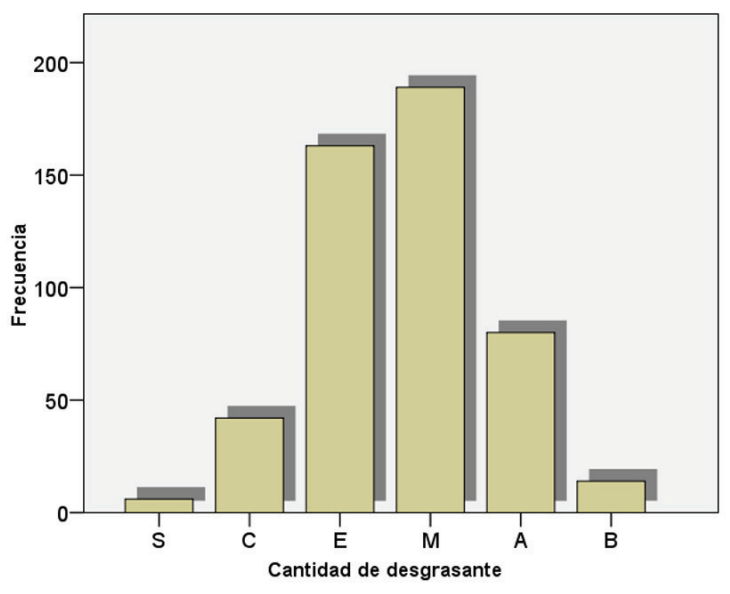

Fig. 10. Cuantificación del desgrasante. $\mathrm{S}$ (sin inclusiones); C (muy escasos); E (escasos); M (cantidad media); A (abundantes); B (muy abundantes).

\subsubsection{Otras acciones tecnológicas}

Para completar la información referente a los atributos tecnológicos se han recopilado otra serie de indicadores relativos a las técnicas de manufactura y/o reparación (Tabla 4)

A nivel tecnológico, resulta interesante la identificación de vasijas confeccionadas con molde (M). Sólo se ha constatado la existencia de seis recipientes que conserven la impresión sobre la cara externa (concretamente se trata de dos platos, un vaso carenado, una fuente y una olla ovoide). No obstante son corrientes los bordes vueltos y rematados hacia el exterior, que parecen estar conectados con esta práctica, como método para eliminar los rebordes dejados por el molde cerca del labio. Otra técnica de manufactura documentada es la aplicación de capas de arcilla con posterioridad al modelado primario para engrosar algunas paredes, regularizar superficies o igualar

\begin{tabular}{|ll|r|r|}
\hline $\begin{array}{l}\text { Otras acciones } \\
\text { tecnológicas }\end{array}$ & $\begin{array}{c}\text { Fre- } \\
\text { cuencia }\end{array}$ & $\begin{array}{c}\text { Porcen- } \\
\text { taje }\end{array}$ \\
\hline Pasta poco cocida & $\mathrm{C}$ & 437 & 89,1 \\
Huella digital impresa & $\mathrm{I}$ & 14 & 2,8 \\
Molde & $\mathrm{M}$ & 6 &, 2 \\
Superficie igualada con capa & $\mathrm{S}$ & 6 & 1,2 \\
de barro & & 19 & 1,2 \\
Tratamiento superficial especial & $\mathrm{T}$ & 11 & 2,8 \\
Huella vegetal impresa & $\mathrm{V}$ & 494 & 100,0 \\
& $\mathrm{~T}$ & & \\
\hline
\end{tabular}

Tabla 4. Casos y porcentaje de otras acciones tecnológicas. 
el trazado de los bordes (S), documentada en dos orzas, tres ollas y un vaso carenado. Durante el proceso de manufactura, alguna superficie quedó marcada de forma accidental con marcas digitales (I). El empleo puntual de desgrasante vegetal, también dejó improntas sobre las dos superficies de toda la vajilla del asentamiento (V). Entre las técnicas de acabado existen tratamientos de superficie de gran calidad (T), con bruñidos intensos que, como expusimos, están asociados casi de forma exclusiva a vasos y cazuelas carenadas. Finalmente, con relación al proceso de cocción, se ha documentado la anomalía de catorce fragmentos con matriz deleznable y propiedades que en otros yacimientos, como Cuesta del Negro (Purullena, Granada) (Contreras 1986) están relacionadas con temperaturas bajas durante la cocción. El porcentaje es mayor, pero solo se han registrado los casos en los que esta irregularidad es evidente.

A otro nivel, en la muestra estudiada no hemos reconocido ningún lañado o pulimentado de los bordes, vinculado al reaprovechamiento o reutilización de las cerámicas. En este sentido, la única práctica de reciclado visible es el recorte de fragmentos ("fichas") de diferentes diámetros, con objeto de darles un uso que por el momento desconocemos, a pesar de ser una costumbre bastante común en otros asentamientos prehistóricos de la Edad del Bronce como Motilla del Azuer, Motilla de las Cañas, Motilla del Retamar, La Encantada o Cerro de la Encina, por citar algunos ejemplos. (Fig. 6: 40-42).

\subsubsection{Elementos de sujeción (Tabla 5)}

Solamente un 3,8 \% de los fragmentos sometidos a análisis incluye algún sistema de sujeción. Los instrumentos de aprehensión más usados son los mamelones, que aparecen de forma exclusiva en varias clases de ollas y alguna orza. Los de forma cónica son los más abundantes, seguidos de los de lengüeta, troncocónicos, suaves y los cilíndricos. Existen dos vasijas con mamelones dobles ligeramente separados: una olla globular con dos mamelones cónicos (Fig.3: 3) y una olla ovoide con dos pequeños mamelones cilíndricos cerca del borde (Fig. 3: 9). Con relación a las asas, no se ha podido establecer ninguna asociación a formas o tipos cerámicos determinados, debido a que se ha conservado solamente la zona del asa. Por otra parte, como técnica de suspensión contamos con una doble perforación cerca del borde en un plato hondo con el fondo plano (Fig. 4: 24).

\begin{tabular}{|c|c|c|c|}
\hline \multicolumn{2}{|l|}{ Elementos de sujeción } & \multirow{2}{*}{$\begin{array}{r}\text { Frecuencia } \\
475\end{array}$} & \multirow{2}{*}{$\begin{array}{r}\text { Porcentaje } \\
96,2\end{array}$} \\
\hline & - & & \\
\hline Asa anular & EAA & 1 & ,2 \\
\hline $\begin{array}{l}\text { Asa/mamelón } \\
\text { indeterminada/o }\end{array}$ & EAM & 1 & ,2 \\
\hline $\begin{array}{l}\text { Asa de sección oval- } \\
\text { elíptica }\end{array}$ & EAO & 1 & ,2 \\
\hline $\begin{array}{l}\text { Lengüeta/orejeta no } \\
\text { perforada }\end{array}$ & ELN & 3 & 6 \\
\hline $\begin{array}{l}\text { Mamelón suave en el } \\
\text { borde }\end{array}$ & EMB & 1 & ,2 \\
\hline Mamelón cónico & EMC & 6 & 1,2 \\
\hline Mamelón suave & EMS & 2 & ,4 \\
\hline Mamelón troncocónico & EMT & 2 & ,4 \\
\hline Mamelón cilíndrico & EMY & 1 & ,2 \\
\hline \multirow[t]{2}{*}{ Perforación } & EPE & 1 & ,2 \\
\hline & Total & 494 & 100,0 \\
\hline
\end{tabular}

Tabla 5. Elementos de aprehensión y suspensión documentados.

\begin{tabular}{|c|c|c|c|}
\hline \multicolumn{2}{|l|}{ Decoración } & \multirow{2}{*}{\begin{tabular}{r|} 
Frecuencia \\
421
\end{tabular}} & \multirow{2}{*}{$\begin{array}{r}\text { Porcentaje } \\
85,2\end{array}$} \\
\hline & 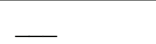 & & \\
\hline $\begin{array}{l}\text { Cordón liso } \\
\text { exterior }\end{array}$ & CLE & 1 & ,2 \\
\hline $\begin{array}{l}\text { Impresa pun- } \\
\text { tillada exte- } \\
\text { rior, Incisa } \\
\text { exterior }\end{array}$ & IAE,INE & 1 & ,2 \\
\hline $\begin{array}{l}\text { Impresa } \\
\text { digitada labio }\end{array}$ & IDL & 30 & 6,1 \\
\hline $\begin{array}{l}\text { Impresa } \\
\text { espátula/pun- } \\
\text { zón labio }\end{array}$ & IEL & 29 & 5,9 \\
\hline Incisa borde & INB & 1 & ,2 \\
\hline $\begin{array}{l}\text { Incisa exte- } \\
\text { rior }\end{array}$ & INE & 1 & ,2 \\
\hline $\begin{array}{l}\text { Incisa exte- } \\
\text { rior, puntilla- } \\
\text { da interior, } \\
\text { incisa inte- } \\
\text { rior }\end{array}$ & INE,IAI,INI & 1 & ,2 \\
\hline $\begin{array}{l}\text { Incisa exte- } \\
\text { rior, incisa } \\
\text { interior }\end{array}$ & INE,INI & 8 & 1,6 \\
\hline \multirow[t]{2}{*}{$\begin{array}{l}\text { Incisa inte- } \\
\text { rior }\end{array}$} & INI & 1 & ,2 \\
\hline & Total & 494 & 100,0 \\
\hline
\end{tabular}

Tabla 6. Técnicas decorativas identificadas. 


\subsubsection{Decoración}

Se trata de la segunda variable cualitativa no tecnológica sometida a estudio, tras los elementos de sujeción. Para su análisis se ha considerado la técnica decorativa y la posición, acompañadas por una descripción de determinados motivos y estilos decorativos (Tabla 6).

Aproximadamente un $15 \%$ del conjunto está decorado. Si descomponemos los datos por técnicas comprobaremos que en un $80,8 \%$ se realizaron impresiones, en un $15 \%$ incisiones, en dos casos se combinaron ambos procedimientos y a una vasija se le aplicó un cordón. Ahora bien, casi todas las impresiones son sencillas y consisten en dejar marcado el labio de las vasijas con series realizadas con la yema de los dedos, punzones u otros instrumentos. Como ocurre en otros yacimientos de la Edad del Bronce, las impresiones digitadas se aplicaron principalmente sobre el labio de orzas y las impresiones de punzón sobre el labio de diferentes tipos de ollas.

Las incisiones fueron realizadas con trazos finos, formando motivos más complejos. En tres fragmentos de paredes finas, claramente vinculados a lo que se ha denominado tradicionalmen-

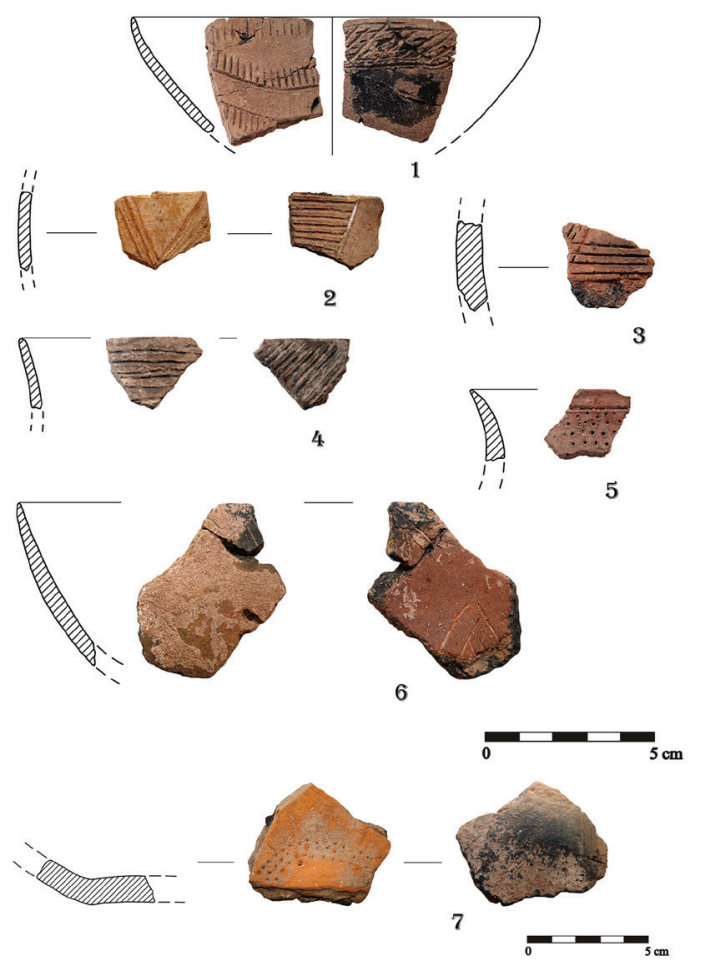

Fig. 11. Distintos tipos de decoraciones incisas (1, $2,3,4,5,6,7)$ e impresas $(5,7)$. te como fenómeno campaniforme inciso tardío, estilo Ciempozuelos o Dornajos, aparecen decoraciones tanto al exterior como al interior. El primero, un cuenco (Fig. 11: 1) muestra al exterior una banda cerca del borde formada por trazos cruzados, flanqueada por otras dos líneas continuas y al interior trazos cortos verticales paralelos acompañados por líneas continuas horizontales. El segundo fragmento pertenece a la zona intermedia de la pared de una vasija (Fig. 11: 2) y está decorado al exterior con varias líneas paralelas que forman un zig-zag, con un vértice bien definido, mientras que al interior presenta líneas horizontales paralelas delimitadas por otra en vertical, ligeramente oblicua. El tercero es un borde, seguramente de un vaso (Fig. 11: 4), con líneas paralelas horizontes en la pared externa y totalmente oblicuas en la interna. En otro caso, un borde fino del mismo estilo, se localiza un trazo continuo longitudinal combinado con un puntillado de la propia línea y toda la superficie exterior (Fig. 11: 5). En vasijas menos cuidadas, en lo que se refiere a modelado, grosor de las paredes, tratamiento superficial o las propias decoraciones, encontramos decoraciones similares, con líneas paralelas, cruzadas, formando zig-zag, trazos cortos, galones, o círculos, con decoración en una o en las dos caras (Fig. 11: 3, 6). En un caso singular, se aprovechó la zona central interna de un fondo rehundido para crear un motivo esquemático soliforme, confeccionado con una banda circular de puntillado, rodeada por incisiones cortas, representando los rayos (Fig. 11: 7). Este último fragmento también tiene decorado el exterior con incisiones en zig-zag.

A nivel de aplicaciones plásticas solo se ha identificado un cordón liso adosado al galbo de una forma sin identificar. Algunos mamelones suaves o cilíndricos que hemos descrito en el apartado anterior también debieron tener una finalidad decorativa..

\subsubsection{Alteraciones por el uso y los efectos postdeposicionales}

Se han contemplado determinadas señales y evidencias derivadas del uso, amortización y abandono final de los recipientes (Tabla 7).

No resulta sencillo determinar si algunas alteraciones se produjeron durante el uso de los recipientes o tras su abandono. En el caso de las alteraciones térmicas, contamos con seis fragmentos que muestran el color y tizne característicos de haber estado expuestos al fuego reiteradamente 


\begin{tabular}{|ll|r|r|}
\hline Alteraciones & & Frecuencia & Porcentaje \\
\hline & & 73 & 14,8 \\
Alteración térmica & $\mathrm{A}$ & 36 & 7,3 \\
Concreción & $\mathrm{C}$ & 380 & 76,9 \\
Marcas/estrías & $\mathrm{M}$ & 5 & 1 \\
& Total & 494 & 100,0 \\
\hline
\end{tabular}

Tabla 7. Parámetros y casos de la variable alteraciones.

y otros tres con la pasta al borde de la vitrificación, como consecuencia de soportar temperaturas muy elevadas. En el resto (28) no es posible determinar el origen de la actividad o suceso que provocaron su quemado, aunque sabemos que la mayoría son ollas y orzas.

Las marcas y arañados (M) que hemos detectado, corresponden a un cuenco, una fuente y a varios vasos con una franja desgastada cerca del borde o por debajo de la línea de carena, que debió producirse al apoyarlos sobre un soporte con cierto poder abrasivo.

La principal afección de los fragmentos tras su deposición ha sido la aparición de concreciones de tipo calcáreo adherida a las paredes $(76,9 \%)$, que han dificultado además, el estudio del conjunto, al cubrir en muchas ocasiones la totalidad de la superficie de las cerámicas.

\section{Conclusiones}

En Castillejo de Bonete está representado todo el repertorio de formas cerámicas que caracteriza una instalación como pueda ser una motilla. Se han registrado vasijas propias de las actividades cotidianas que son corrientes en cualquier otros asentamientos coetáneos. Los porcentajes y recurrencia de cada conjunto formal y funcional también coinciden con esta afirmación. No obstante, los contextos localizados aquí son muy diferentes a los usos hasta ahora descritos como habitacionales. El interior de la sima natural y el resto de estructuras documentadas hasta el momento son compartimentaciones funcionales y de circulación derivadas del uso continuado en diferentes fases del complejo tumular.

En el yacimiento también se han ido sucesivamente excavando una serie de fosas oferentes, a modo de vaciados circulares, donde se depositaban las ofrendas y posteriormente se introducía el relleno retirado previamente. En esas fosas se han locali- zado un conjunto de formas cerámicas formado por cinco ollas, tres orzas y un cuenco, que pensamos que nos están informando sobre la reiteración de ritos de comensalidad a una escala inferior.

Por lo tanto, los contextos arquitectónicos y arqueológicos de esta colección cerámica tienen un carácter ritual y funerario, por lo que habrá que esperar a futuras investigaciones para poder resolver la presencia del amplio repertorio formal y funcional documentado en Castillejo de Bonete.

Por el momento el conjunto examinado en este estudio muestra un repertorio de cocina en el que se usan ollas ovoides simples, relacionadas por su forma, características tecnológicas y deposición de hollín en la superficie externa, con la preparación de alimentos o el almacenaje de productos. Asimismo existen formatos globulares que, por la morfología de las piezas, sugieren un uso potencial como contenedores de líquidos. En cambio las ollas de perfiles ovoides y globulares, con el cuello terminado en un borde más abierto, forman parte del grueso de la vajilla de cocina y están relacionadas, por sus parámetros morfológicos y deposición de hollín con la cocción de alimentos que pudieran requerir un nivel de evaporación lento. Las de mayor volumen pudieron ser usadas también para el almacenaje o depósito de diferentes contenidos. Dentro del conjunto de contenedores de gran tamaño se han identificado también perfiles ovoides, carenados y con el cuerpo inferior globular u ovoide, cuello marcado y borde saliente. Por ahora no conocemos el tipo de productos que contendrían en Castillejo del Bonete. No obstante, en yacimientos como la Motilla del Azuer (Nájera y Molina 2004; Fernández, 2012) o la Motilla del Retamar (Lenguazco 2012), las orzas y especialmente el último tipo descrito, están asociadas al almacenamiento de grandes cantidades de cereal. El grupo de cuencos y vasos estaría dedicado al consumo de diferentes alimentos sólidos o líquidos, de forma individual o colectiva, dependiendo del tamaño.

De cualquier manera debemos señalar que muchos de los elementos cerámicos prehistóricos serían polifuncionales, sobre todo los tipos básicos y aquellos que abarcan un abanico de tamaños extenso o poco especializado en cuanto a su relación forma-contenido, como es el caso. En el caso de las fuentes y cazuelas carenadas es aún más difícil determinar el uso. Las primeras son una expresión volumétrica desarrollada de los cuencos y las segundas lo son de los vasos 
carenados. Sólo una fuente muestra alteraciones térmicas, mientras que ninguna cazuela presenta evidencias de exposición al fuego, de manera que pudieron ser empleadas tanto para el consumo como para la preparación o almacenamiento puntual de productos a nivel doméstico.

El tamaño, unido a los atributos tecnológicos de los vasitos muy pequeños, los hace singulares dentro de la muestra. Los tres ejemplares ovoides sin cuello evidencian una factura muy elaborada, con paredes muy finas y tratamientos cuidados. El producto es semejante al de algunos tipos de cerámica naranja de la Edad del Cobre. Estas características se manifiestan y resultan más evidentes en uno de los vasitos, semejante incluso en el color. En vista de su tamaño y rasgos, su producción estaría bastante estandarizada. Para esta forma y tamaño proponemos un uso conectado con el consumo de algún producto particular, que fuese preciso o apropiado ingerir en pequeñas dosis.

Las queseras, que en mayor o menor medida están presentes en los asentamientos prehistóricos desde el Neolítico, han generado a lo largo de tiempo controversia sobre su función y denominación. Actualmente, gracias a los análisis de lípidos, cada vez son menos los que dudan sobre su vinculación con la elaboración de queso u otro producto lácteo (Itan et al. 2009; Salque et al. 2013). Los dos fragmentos conservados siguen los patrones característicos, con perforaciones circulares realizadas desde el exterior, por las que saldría el suero sobrante, al presionar la pasta láctea cuajada. El fragmento que conserva el borde de la boca, pertenece a un ejemplar troncocónico con cuello ligeramente indicado cerca del borde (Fig. 6: 43).

En consecuencia, a través del estudio realizado se puede deducir que en este complejo tumular se almacenaron y procesaron productos $\mathrm{u}$ objetos, se cocinó, se bebió y se comió habitualmente, bien como parte de las actividades realizadas durante la ocupación del conjunto arquitectónico o como parte de algunos ritos de comensalidad.

En cuanto a otras actividades asociadas a la cerámica se puede indicar que hasta el momento no ha sido encontrado ningún fragmento de crisol, o que muestre evidencias relacionadas con la producción, transformación o reciclado de metal.

Con independencia de las cuestiones meramente formales o funcionales, la segregación y estudio de cada una de las variables tecnológicas ha hecho posible que conozcamos parte del proceso productivo. Para saber dónde se produjo la captación de materias primas sería necesario promover análisis futuros. Lo que sí sabemos, según las matrices con ausencia de inclusiones y la variabilidad en cuanto al contenido de antiplásticos que presentan los distintos elementos de la vajilla, es que las pastas se decantaron y que el desgrasante se preparó con antelación al amasado, machacándolo, si nos atenemos a las aristas que presentan los granos examinados y a la fracturación de inclusiones documentada con el microscopio en el interior de algunas matrices. En algún caso aislado también se empleó desgrasante vegetal o chamota (cerámica triturada). En cuanto al modelado, la metodología que hemos utilizado no nos permite conocer con precisión las técnicas, pero los puntos de ensamblaje registrados en orzas y formas carenadas así como las improntas en las caras externas de las vasijas coinciden con las documentadas en otros yacimientos como Motilla del Azuer o Cerro de la Encina: ahuecado o pellizcado (obteniendo una vasija, a partir de una sola pella de arcilla), superposición de aros o churros de arcilla y molde. La diferencia con respecto a otros yacimientos la marca el número de vasijas elaboradas con esta última técnica, siendo bastante mayor en nuestro caso. Las cerámicas se rematarían con el aplique de los elementos de sujeción y decoración, cuando la pasta aún estaba en textura de cuero. En la terminación de las superficies se optó principalmente por el alisado, usando instrumentos fibrosos que han dejado marcas finas y otros que han dejado trazos más anchos y que podrían ser producto de espátulas, regularizando las dos caras. Por otra parte, aunque también se bruñeron las superficies de una amplia variedad de formas, los datos muestran una preferencia por utilizar esta técnica en vasos y formas carenadas. En cuanto a la cocción, los colores de las superficies y matrices marcan los parámetros propios de cocciones con estructuras sin cámara con la salvedad de una parte de la muestra, que presenta deficiencias de temperatura, y para la que no descartamos su cocción en entornos más simples.

De la suma de las observaciones y de lo visto hasta el momento se puede extraer que existe un conjunto de cerámicas con matrices poco sinterizadas y con escasa consistencia de sus constituyentes, en las que predominan los colores y tonos claros de superficie, junto a acabados alisados. También hemos descubierto que algunas de estas vasijas se fabricaron con molde. A través de las secciones hemos podido averiguar que suelen tener una transición cromática en la sección y 
que la adecuación de la cantidad de desgrasante y otras técnicas a la forma de la vasija no está generalizada y, por lo tanto, tampoco lo estaría la especialización funcional de las técnicas y los materiales a las formas confeccionadas. Dentro de la colección se encuentran tipos característicos de las fases finales del Cobre Final y de las iniciales del Bronce Antiguo, si consideramos los tipos existentes en otros yacimientos de la región, que conocemos y que están aún por publicar.

Por otra parte, contamos con otro grupo de cerámicas con coloraciones y tonos más oscuros, un mayor porcentaje de bruñidos y con predominio de matrices con varias transiciones cromáticas en la sección. A este nivel, no se han identificado deficiencias claras de temperatura y es obvio que en su confección se desarrollaron pastas más estandarizadas dentro del conjunto cerámico, como ocurre con los tratamientos y acabados, con respecto a cada tipo o grupo formal. Esta cuestión es perceptible en tipos de ollas, cuencos y fuentes, característicos del Bronce de La Mancha, y encuentra su máxima expresión en algunos tipos de contenedores de almacenaje, en cuanto a la regulación en el añadido de desgrasante. Pero sobre todo se pone de manifiesto en los vasos y cazuelas carenadas, en los que la simetría y regularidad de las paredes, el tratamiento de superficie, además de la menor cantidad de desgrasante, que produce pastas más depuradas, matrices más compactas y facilita la terminación superficial, superan en calidad al resto. Por tanto, su elaboración debió requerir una mayor dedicación de tiempo y medios, con un resultado más vistoso $\mathrm{y}$, a buen seguro, estéticamente más valorado.

Como elementos distinguidos a nivel tecnológico y simbólico es preciso citar los vasitos muy pequeños de forma ovoide simple, así como a los fragmentos decorados con incisiones y motivos geométricos y simbólicos, entre los que se encuentran los campaniformes, que parecen pervivir en la región manchega en momentos avanzados.

Por el momento no es posible proponer un modelo productivo para Castillejo del Bonete, puesto que no se ha realizado un estudio completo de la muestra cerámica. Pero los primeros resultados permiten plantear una producción no estandarizada, ni normalizada, de la cerámica que aparece en el lugar, cuyos tipos y características tecnológicas, carecen de los patrones que definen la presencia de un artesanado especializado.

\section{Nota}

1. Entendemos por filete el margen exterior al núcleo que tiene un grosor menor de una quinta parte de la sección de la vasija. Entendemos por banda el margen exterior al núcleo que supera el rango del filete.

\section{Agradecimientos}

A los Dres. María Isabel Martínez Navarrete, Susana Consuegra Rodríguez, Pedro Díaz del Río Español, José Antonio López Sáez y Marta Moreno García (CCHS-CSIC), Gonzalo Aranda Jiménez y Margarita Sánchez Romero (Universidad de Granada), Primitiva Bueno Ramírez, Rodrigo de Balbín Behrmann, Rosa Barroso Bermejo (Universidad de Alcalá de Henares) y Antonio Gilman (California State University). Al pueblo de Terrinches, al personal de su Ayuntamiento ya su Alcalde, D. Nicasio Peláez Peláez. Al Servicio de Protección de la Naturaleza (SEPRONA) de la Guardia Civil.

\section{REFERENCIAS BIBLIOGRÁFICAS}

ArANDA JimÉNEZ, G. (2001): El análisis de la relación forma-contenido de los conjuntos cerámicos del yacimiento arqueológico del Cerro de la Encina (Granada, España). British Archaeological Reports. International Series 927, Oxford.

ArAnda JimÉnez, G. (2004): Craft specialization in pottery production during the Bronze Age in southeastern Iberia. Journal of Iberian Archaeology, 6:. 157-179.

Benítez de Lugo Enrich, L.;Álvarez García, H.J.; Fernández Montoro, J.L.; Mata Trujillo, E.; Moraleda Sierra, J.; Sánchez Sánchez, J.; Rodríguez Morales, J. (2012): Excavaciones en la Vía de los Vasos de Vicarello A Gades Romam, entre las estaciones de Mariana y Mentesa (Puebla del Príncipe, Villanueva de la Fuente, Ciudad Real. Archivo Español de Arqueología, 85: 81-97. Doi: 10.3989/aespa.085.012.006. 
Benítez de Lugo Enrich, L.; Mejías Moreno, M.; López Gutiérrez, J.; Álvarez García, H.J.; Palomares Zumajo, N.; Moraleda Sierra, J. (2014a): Aportaciones hidrogeológicas al estudio arqueológico de los orígenes del Bronce de La Mancha: la cueva monumentalizada de Castillejo del Bonete (Terrinches, Ciudad Real-España). Trabajos de Prehistoria, 71 (1): 76-94. Doi: 10.3989/tp.2014.12125.

Benítez de Lugo Enrich, L.; Álvarez García, H.J.; Fernández Martín, S.; Mata Trujillo, E.; Menchén Herreros, G.; Montero Ruiz, I.; Moraleda Sierra, J.; Morgado Rodríguez, A.; Palomares Zumajo, N.; Benito Sánchez; Odriozola Lloret, C.; Ruiz-Alonso, M.; Salazar-García, D.C. (2014b): Castillejo del Bonete (Terrinches, Ciudad Real): complejo tumular prehistórico de la Cultura de las Motillas en el Alto Guadalquivir. Menga, Revista de Prehistoria de Andalucía, 5: 151-173

Benítez de Lugo Enrich, L.; Schuhmacher, T.X.; Palomares Zumajo, N.; Álvarez García, H.J.; Mata Trujillo, E.; Moraleda Sierra, J.; Menchén Herreros, G.; Salazar-García, D.C. (en prensa): Marfil para los muertos en la Cultura de las Motillas: los botones de Castillejo del Bonete (Terrinches, Ciudad Real). Madrider Mitteilungen, 56. En prensa.

Benítez de Lugo Enrich, L.; Mejías Moreno, M. (en prensa): La prehistórica Cultura de las Motillas: nuevas propuestas para un antiguo problema. Veleia, 32. En Prensa.

CAPel Martínez, J. (1982): Estudio mineralógico y geoquímico de cerámicas y sedimentos arqueológicos de algunos yacimientos de La Mancha. Tesis Doctorales de la Universidad de Granada 494, Granada.

CAPEL MarTínez, J. (1986): Estudio mineralógico y geoquímica de sedimentos y cerámicas arqueológicas de algunos yacimientos de La Mancha. Oretum, II: 55-156.

Contreras Cortés, F. (1984): Clasificación y tipología en Arqueología. El camino hacia la cuantificación. Cuadernos de Prehistoria de la Universidad de Granada, 9: 327-385.

CONTRERAs CORTÉs, F.(1986): Aplicación de métodos estadísticos y analíticos a los complejos cerámicos de la Cuesta del Negro (Purullena, Granada). Tesis doctorales de la Universidad de Granada microfilmadas, Granada.

Contreras, F.; CÁmara, J. A. (2000): El poblado de la Edad del Bronce de Peñalosa (Baños de la Encina, Jaén). La cerámica. Análisis Histórico de las Comunidades de la Edad del Bronce del piedemonte meridional de Sierra Morena y Depresión Linares-Bailen. Proyecto Peñalosa (F. Contreras, coord.), Arqueología. Monografías 10:, Sevilla 77-128, , (incluye 91/2-91/46 y 109/5 en CD-ROM).

Costin, C. (2005): Craft Production. Handbook of Archaeological Method. (H. D. G. Maschner; C. Chippindale, eds.), Altamira Press, Lanham: 1084-

Fernández Martín, S. (2005): Estudio morfométrico de la producción cerámica del yacimiento arqueológico de la Edad del Bronce de la Motilla del Azuer (Daimiel, Ciudad Real). Arqueología y Territorio 2, http://www.ugr.es/ arqueol/.

Fernández Martín, S.(2008): Análisis tipológico y tecnológico de los conjuntos cerámicos de la Motilla del Azuer (Daimiel, Ciudad Real). Cuadernos de Prehistoria y Arqueología de la Universidad de Granada, 18: 317-356.

FERNÁNDEZ MARTín, S.(2012): Clasificación tipológica de la cerámica del yacimiento de la Edad del Bronce de la Motilla del Azuer (Ciudad Real, España). British Archaeological Reports. BAR International Series 2377, Oxford.

Itan, Y.; Powell, A.; Beaumont, M. A.; Burger, J.; Thomas, M. G. (2009): The Origins of Lactase Persistence in Europe. PLoS Comput Biol, 5 (8). Doi: 10.1371/journal.pcbi.1000491

Lenguazco GonzÁlez, R. (2012): Estudio de materiales y análisis de su relación con los contextos excavados en la Motilla del Retamar (Argamasilla de Alba, Ciudad Real). Arqueoymás monografías 3. Madrid

Lull, V.; Micó, R. (1999): Análisis morfométrico y tecnológico de la cerámica funeraria de la Cova des Càrritx.] Ideología y Sociedad en la prehistoria de Menorca. La Cova des Càrritx y la Cova des Mussol (V. Lull; R. Micó, C. Rihuete; C., R. Rich, eds.), Consell Insular de Menorca, Ajuntament de Ciutadella, Fundació Rubió Tudurí Andrómaco, Ciudadela : 581-624

Mathew, A. J.; Woods A. J.; Oliver, C. (1991): Spots before your eyes: new comparison charts for visual percentage estimation in archaeological material. Recent developments in ceramic petrology (A. P. Midleton; C. Freestone, eds), British Museum Occasional Paper, 81: 211-263.

Montero Ruiz, I.; Benítez de Lugo Enrich, L.; Álvarez García, H.J.; Gutiérrez Neira, P.C.; Murillo Barroso, M.; Palomares Zumajo, N.; Menchén Herreros, G.; Moraleda Sierra, J.; Salazar-García, 
D.C. (2014): Cobre para los muertos. Estudio arqueométrico del material metálico procedente del monumento megalítico prehistórico Castillejo del Bonete (Terrinches, Ciudad Real-España). Zephyrus, LXXIII: 109-132. Doi: http://dx.doi.org/10.14201/zephyrus201473109132.

NÁJERA Colino, T. (1982): La Edad del Bronce en La Mancha occidental. Tesis doctoral inédita, Universidad de Granada, Granada.

NÁjera Colino, T.; Molina, F. (2004): La Edad del Bronce en La Mancha Occidental: problemática y perspectivas de la investigación. $1^{\text {as }}$ Jornadas La Edad del Bronce en tierras valencianas y zonas limítrofes (L. Hernández; M. Hernández, eds.), Museo de Villena: 531-540

Nieto Gallo, G.; SÁnchez Meseguer, J. (1980): El Cerro de la Encantada. Granátula de Calatrava (Ciudad Real). Excavaciones Arqueológicas en España, 113 Madrid.

Polo Martín, E., Bueno Ramírez, P., de Balbín Behrmann, R., Benítez de Lugo Enrich, L.; Palomares Zumajo, N. (2015): "Manifestaciones gráficas en la Cueva-Sima del Castillejo del Bonete (Terrinches, Ciudad Real)". Arpi 2: 90-107.

Reimer, P. J.; Bard, E.; Bayliss, A.; Beck, J. W.; Blackwell, P. E.; BronkRamsey, C.; Grootes, P. M.; Gullderson, T. P.; Hajdas, I.; HattZ, C.; Heaton, T. J.; Hoffmann, D. L.; Hogg, A. G.; Hughen, K. A. Kaiser, K.; Kromer, B.; Manning, S.; Niu, M.; Reimer, R. W.; Richards, D.A.; Scott, E. M.; Southon, J.R.; Staff, R. A.; Turner, C. S. M.; Van der Plicht, J. (2013): IntCal13 and Marine13 radiocarbon age calibration curves, 0-50.000 years cal BP. Radiocarbon 55, (4): 1111-1150.

Rice, P. M. (1989): Ceramic Diversity, Production, and Use. Quantifying Diversity in Archaeology (R. D. Leonard; G. T. Jones, eds.), Cambridge University Press, Cambridge: 109-117.

Salazar-García, D.C.; Benítez de Lugo Enrich, L.; Álvarez García, H.J.; Benito Sánchez, M. (2013): Estudio diacrónico de la dieta de los pobladores antiguos de Terrinches (Ciudad Real) a partir del análisis de isótopos estables sobre restos óseos humanos. Revista Española de Antropología Física, 34: 6-14.

Salque, M.; Bogucki, P. I.; Pyzel, J.; Sobkowiak-Tabaka, I.; Grygiel, R.; Szmyt, M.; Evershed, R. P. (2013): Earliest evidence for cheese making in the sixth millennium Bc in northern Europe. Nature, 493: 522-525.

SÁnchez Meseguer, J. (1994): El Cerro de la Encantada y el Bronce Pleno en La Mancha. Jornadas de Arqueología de Ciudad Real en la Universidad Autónoma de Madrid (J. Sánchez Meseguer; D. Peris Sánchez; M. Bendala Galán, coords.). Patrimonio Histórico de Castilla-La Mancha-Arqueología 8. Toledo: 69-86. Sánchez Sánchez, J.; Benítez de Lugo Enrich, L.; Rodríguez Morales, J.; Fernández Montoro, J.L. (2012): Nomenclatura viaria antigua. La vía de los Vasos de Vicarello: una Vía Augusta de Hispania. El Nuevo Miliario, 15: 3-21.

VARGAS, I. (1995): El papel de las tipologías y los sistemas clasificatorios en la interpretación hecha por la Arqueología social. Boletín de Antropología Americana, 31:111-114.

ZedeÑo, M. N. (1985): La relación forma-contenido en la clasificación cerámica. Boletín de Antropología Americana, 11: 18-26, 